\title{
Common Ownership Does Not Have Anti-Competitive Effects in the Airline Industry
}

\author{
Patrick Dennis, Kristopher Gerardi, and Carola Schenone
}

\author{
Working Paper 2019-15 \\ July 2019
}

\begin{abstract}
Institutional investors often own significant equity in firms that compete in the same product market. These "common owners" may have an incentive to coordinate the actions of firms that would otherwise be competing rivals, leading to anti-competitive pricing. This paper uses data on airline ticket prices to test whether common owners induce anti-competitive pricing behavior. We find little evidence to support such a hypothesis, and show that the positive relationship between average ticket prices and a commonly used measure of common ownership previously documented in the literature is generated by the endogenous market share component, rather than the ownership component, of the measure.
\end{abstract}

JEL classification: G33, G34, G38, L41, L11

Key words: common ownership, airline prices, institutional ownership, competition

https://doi.org/10.29338/wp2019-15

The authors thank Manuel Adelino, Ken Ayotte, Raj Aggarwal, Alon Brav, David Chapman, Sudheer Chava, Quinn Curtis, Steven Davido Solomon, Ofer Eldar, Daniel Ferreira, Paolo Fulghieri, Michael Gallmeyer, Todd Gormely (2019 American Finance Association discussant), Luis Felipe Greene, Campbell Harvey, Nadya Malenko, Frank Partnoy, John Pepper, Adriano Rampini, Daniel L. Rubinfeld, Martin Schmalz (2018 Financial Intermediation Research Society discussant), David C. Smith, Laura Starks (2018 European Finance Association discussant), James Weston, Bill Wilhelm, and Toni Whited for their helpful suggestions and discussions. They also thank seminar participants at the Fuqua School of Business-Duke, Georgia Tech, the Federal Reserve Bank of Atlanta, and the University of Virginia. Dennis acknowledges funding support from the Summer Research Fund at the McIntire School of Commerce. The views expressed here are those of the authors and not necessarily those of the Federal Reserve Bank of Atlanta or the Federal Reserve System. Any remaining errors are the authors' responsibility.

Please address questions regarding content to Kristopher Gerardi, Research Department, Federal Reserve Bank of Atlanta, 1000 Peachtree Street NE, Atlanta GA, 30308-4470, kristopher.gerardi@atl.frb.org; Patrick Dennis, University of Virginia, McIntire School of Commerce, East Lawn, P.0. Box 400173, Charlottesville, VA 22904-4173, pdennis@virginia.edu; or Carola Schenone, University of Virginia, McIntire School of Commerce, East Lawn, P.0. Box 400173, Charlottesville, VA 22904-4173, schenone@virginia.edu.

Federal Reserve Bank of Atlanta working papers, including revised versions, are available on the Atlanta Fed's website at www.frbatlanta.org. Click "Publications" and then "Working Papers." To receive e-mail notifications about new papers, use frbatlanta.org/forms/subscribe. 
The role of institutional investors in financial markets has increased dramatically over the past few decades, with the institutional share of publicly traded equity rising from 33 percent in 1980 to 61 percent in 2018. ${ }^{1}$ This trend has been accompanied by significant interest from researchers, who have focused on determining the economic costs and benefits of large financial institutions managing funds on behalf of smaller investors. The benefits of institutional ownership are welldocumented, and include increased exposure to many asset classes that would not otherwise be available to small, individual investors. Perhaps even more important is the increased ability of small investors to diversify their investments at low cost using asset managers who are able to take advantage of economies of scale in portfolio diversification.

The costs of institutional ownership are less clear. Institutional investors often own significant equity in multiple firms, including those that compete in the same product market. This creates the potential for investors to coordinate the actions of firms that would otherwise be competing rivals. Specifically, institutional investors could induce, or even mandate, anti-competitive pricing behavior among product market rivals within their portfolios.

The potentially negative effects of common ownership on product market competition has resonated with both legal scholars and policymakers, and has put significant pressure on anti-trust authorities to open formal investigations into the potentially anti-competitive effects of institutional ownership. It has also spawned a relatively new empirical literature that has begun to analyze the potentially negative effects of common ownership on product market competition. For instance, Azar, Schmalz, and Tecu (2018a) and Azar, Raina, and Schmalz (2016) claim to find evidence of a causal relationship between the concentration of common ownership and average prices in a market. Based, in part, on these findings, Posner, Morton, and Weyl (2017) have proposed that Congress enact legislation to withdraw tax advantages for retirement funds investing in any mutual fund that owns a significant number of shares in multiple firms in the same industry, and that investors "limit their holdings of an industry to a small stake (no more than $1 \%$ of the total size of the industry) or hold the shares of only a single 'effective firm' per industry." The authors further propose that if large index funds prefer to continue business as usual, legislation should force such funds to commit to governance "passivity," ceasing all engagement with portfolio companies:

\footnotetext{
${ }^{1}$ Institutional ownership data come from Thomson Reuters and U.S. stock market capitalization data comes from CRSP. These percentages are measured at the end of the first quarter of each year.
} 
"No institutional investor or individual holding shares of more than a single effective firm in an oligopoly may ultimately own more than one percent of the market share or directly communicate with the top managers or directors of firms." Elhauge (2015) argues that legislative change is not required under current U.S. anti-trust laws, but what is required is the enforcement of the already enacted Clayton Act (specifically $§ 7$ ) to challenge any stock acquisition that results in a common set of investors owning significant shares in corporations that are horizontal competitors, since the statute already bans any such stock acquisitions.

Legislation restricting asset managers from freely investing in a diversified portfolio would have severe consequences for the industry, individual investors, and, potentially, the economy as a whole. Index funds could be forced to "split up" so that individual funds within the fund family do not collectively surpass the one percent ownership limit in an industry. These proposals could also distort fund management strategies, impose heavy monitoring costs on the funds and regulators (as they would need to continuously track every market in which a fund has investments to ensure no changes have occurred that would require the sale of shares), create substantial uncertainty in investment strategies, and ultimately raise fees for individual investors. The consequences of such legislation would further extend to the corporate governance of firms. Institutions have been encouraged to monitor firm performance to alleviate the principal-agent problems that arise from the separation of ownership and control. Forcing institutions into governance "passivity" could undo such efforts.

Given the potentially severe consequences of such legislation, this paper revisits the empirical evidence on whether institutional common ownership has anti-competitive effects in product markets. In contrast to the Azar et al. (2018a) analysis (hereafter AST), this paper does not find evidence to support the claim that common ownership leads to anti-competitive pricing effects in the airline industry. Our results show that the positive relationship between common ownership and ticket prices documented by AST is spurious, and generated by the endogenous market share component, rather than the ownership component, of the common ownership measure used in the paper.

Our analysis begins by reconstructing the main AST data sample and closely replicating the primary AST pricing regressions (Table III in their paper). ${ }^{2}$ This is a regression of airline ticket

\footnotetext{
${ }^{2}$ We use code posted by AST on the Journal of Finance website, combined with our own versions of the primary
} 
prices on a measure of common ownership, termed MHHI (Modified Herfindahl-Hirschman Index), and a set of control variables. MHHI was developed by Bresnahan and Salop (1986) and O'Brien and Salop (2000) in the context of cross-ownership (a firm owning equity in a product market rival), and equals the sum of the traditional Herfindahl-Hirschman Index, HHI, which captures concentration in market shares, and an additional term, $H H I \Delta$, which captures the increased concentration in a market created by cross-ownership $(M H H I=H H I+H H I \Delta)$. AST extrapolate from cross-ownership and apply the HHID measure to common ownership (an independent investor owning equity in firms that compete in the same product market). HHI $\Delta$ is a function of both market shares and the cash flow and control rights owned by institutional investors in all firms serving a particular market. AST interpret the positive and statistically significant coefficient estimate associated with $H H I \Delta$ as the causal effect of common ownership on product market prices. This is problematic for two reasons. First, $H H I \Delta$ and $H H I$ are functions of market shares and the industrial organization literature has recognized since Evans, Froeb, and Werden (1993) that: "concentration causes price, but price also causes concentration." Second, since HHID is a function of both market shares and common ownership, the casual effect of common ownership on prices could be confounded by the (endogenous) market share component of HHID.

We first demonstrate that the positive relationship between HHID and ticket prices documented by AST is driven by variation in airline market shares, rather than variation in common ownership among institutional investors, using a placebo analysis. To this end, we construct two alternative measures of $H H I \Delta$ : One where variation in market shares is muted while variation in common ownership is retained; and a second measure, where variation in common ownership is muted while variation in market shares is retained. We find that the first measure is uncorrelated (or negatively correlated in some specifications) with average prices, while the second measure is positively correlated with prices. This shows that it is variation in market shares, not in ownership, that drives the correlation between $H H I \Delta$ and prices. This finding is important, as AST interpret their results as showing that increased common ownership by institutional investors creates anticompetitive effects that result in higher airline ticket prices. However, since the results are driven by variation in market shares and not common ownership, there are no obvious policy implications of the findings.

airline ticket data and the institutional investor ownership data. 
Next, having established that variation in market shares is the source of the positive relationship between average prices and $H H I \Delta$, we address the endogeneity of market shares in the pricing regressions. Following Evans et al. (1993) we combine a fixed effects specification with instrumental variables to eliminate the endogeneity bias from the inclusion of market shares. To instrument for market shares, we follow the methodology developed by Borenstein (1989) and Borenstein and Rose (1994), which uses an airline's presence at the endpoint airports in a market as an instrument. Following this approach, we find little evidence of a positive relationship between airline prices and HHI $\triangle$.

We then provide additional empirical evidence that corroborates our finding that the positive relationship between prices and $H H I \Delta$ is principally driven by spurious correlation between prices and market shares. Specifically, we show that different assumptions regarding the aggregation of cash flow and voting rights across funds in the same fund family do not materially affect the relationship between $H H I \Delta$ and ticket prices. These different aggregation assumptions affect the ownership and control components of the common ownership measure while largely keeping the variation in the market shares component unchanged. Consistent with our placebo tests, and our interpretation of spurious correlation, we find that the regression results are not sensitive to these different aggregation methods. This is in contrast to the claims in Azar, Schmalz, and Tecu (2018b).

In the remainder of the paper we show that the positive relationship between airline prices and $H H I \Delta$ is sensitive to other key data assumptions that materially affect the variation in both components of $H H I \Delta$. For example, we show that the relationship is sensitive to assumptions about the extent of investor control in periods of bankruptcy, which were relatively common in the airline industry during our sample period (2001-2014). The AST analysis assumes that shareholders retain ownership and control of the insolvent firm, and compute HHI $\Delta$ by filling in missing values of cash flow and control rights during bankruptcy with pre-bankruptcy values. However, when a firm operates under bankruptcy protection, existing shareholders typically do not retain cash flow or control rights in the insolvent firm. In fact, when a firm files for bankruptcy protection, the fiduciary duties of management are primarily to creditors, because creditors are the residual claimants in insolvent firms. ${ }^{3}$ Therefore, we recompute HHI $\Delta$ assuming equity holders lose ownership and control in the insolvent firm, and find that the relationship between common ownership and airfares

\footnotetext{
${ }^{3}$ See, for example, Becker and Stromberg (2012), Ayotte and Morrison (2009), and Silberglied (2015).
} 
is significantly attenuated. This alternative assumption sets the values of the ownership and control parameters in the HHID measure to zero, which effectively alters the time-series variation in market shares. ${ }^{4}$

In addition, we find that the AST regression estimates are sensitive to assumptions about the measurement of investor control. The AST analysis uses an institutional owner's reported voting rights to proxy for the owner's control over the airline manager who is making pricing decisions. However, we argue that reported voting rights are noisy and unreliable. We find that voting designations are inconsistent both across institutions and within institutions over time. ${ }^{5}$ We show that an alternative assumption that simply sets control equal to ownership (and does not use reported voting rights) yields a significantly weaker relationship between average prices and

\section{$H H I \Delta$.}

Finally, we show that the positive relationship between prices and $H H I \Delta$ is sensitive to the use of regression weights. The AST analysis uses airline passenger counts as weights in all regression specifications, and consequently places more emphasis on high-traffic markets. While there is no explicit economic justification provided by AST for employing weights, if the authors meant to emphasize markets that are more profitable, then the choice of passenger counts as weights is flawed, as more passengers might result in higher revenues, but also in higher costs, and thus the net effect is unclear. Re-estimating the pricing regressions without weights yields significantly lower conditional correlations between the extent of common ownership and average ticket prices in a market. $^{6}$

Taken together, our results suggest that common ownership does not exert a causal effect on airline ticket prices. Rather, they are consistent with (i) variation in market shares, not ownership, identifying the effect, and (ii) market share endogeneity generating spurious correlation between the measure of common ownership and average prices. This evidence should be taken into consideration in policy discussions around potential regulation of common ownership in product markets.

\footnotetext{
${ }^{4}$ Since market shares and the ownership/control parameters enter multiplicatively in $H H I \Delta$, setting ownership/control to zero during bankruptcy in a particular quarter is equivalent to setting market shares equal to zero for that carrier.

${ }^{5}$ For instance, Fidelity claims no control (reports no voting rights) for 91.2 percent of the airline shares owned during our sample period, while Vanguard first reports that it has voting rights for all of its shares, but then beginning in the third quarter of 2005, reports 100 percent of its shares owned as having no voting rights.

${ }^{6}$ Consistent with this pattern, we provide evidence that the effect of common ownership on average prices is largely driven by the top decile of markets in the passenger count distribution.
} 
Our study complements work by Kennedy, O'Brien, Song, and Waehrer (2017) (KOSW hereafter), who argue that the relationship AST posit between common ownership and airline prices does not follow from the theoretical construct of the theory of common ownership. KOSW show that in the theory of partial ownership both price and the MHHI are equilibrium effects that depend on cost and demand factors, as well as the structure of ownership and control in the market. KOSW show that the reduced form regressions estimated by AST do not follow directly from the theory, and further that AST's results do not hold in a structural model in which the measure of common ownership is directly derived from theory.

The rest of the paper is organized as follows. Section I introduces the measure of common ownership used by AST, reconstructs their dataset, and replicates the paper's main regression results. Section II disentangles variation in the measure of common ownership due to variation in market shares and variation in ownership and control. Section III addresses the endogeneity of airline market shares in the AST pricing regressions. Section IV shows that different strategies to aggregate ownership across funds in a fund family do not materially affect the results. In Section V, we show that the AST results are sensitive to the treatment of ownership and control during airline bankruptcy periods, to assumptions about the mapping between reported voting designations and the extent of managerial control held by investors, and finally, to the inclusion of regression weights that give more emphasis to highly trafficked markets. Finally, Section VI offers some brief concluding remarks.

\section{Revisiting the AST Analysis}

In this section we present the baseline framework and assumptions of Azar et al. (2018a), focusing on data construction, the measure of common ownership, and the primary econometric analysis.

\section{A. Measure of Common Ownership and Econometric Specification}

O'Brien and Salop (2000) derive a theoretical measure of cross ownership that results from a manager maximizing the profits accruing to an owner of her firm as well as profits accruing to the owner from equity stakes in the manager's product market rivals. This measure, termed $H H I \Delta$, 
is closely related to the traditional measure of industry concentration, the Herfindhal Index, $H H I$, which equals the sum of the squared market shares of each firm in the industry: $H H I=\sum_{j} s_{j}^{2}$. Just as $H H I$ measures the extent of product market concentration in an industry, $H H I \Delta$ measures the additional market concentration in an industry due to cross ownership. AST extrapolate from the theoretical construct of O'Brien and Salop (2000) for cross ownership, and apply $H H I \Delta$ to an empirical setting for common ownership. ${ }^{7}$

Formally, HHI $\Delta$ is derived from the first order conditions of the maximization problem faced by the manager of firm $j$. Each owner of firm $j$ also owns equity stakes in firm $j$ 's product market rivals. Manager $j$ 's objective is to maximize the weighted sum of the total profits accruing to all owners in firm $j$, both from firm $j$ and from firm $j$ 's product market rivals, where the weights are the control rights that each owner $i$ has over firm $j$. Owner $i$ 's profit from their ownership stake in all firms in the product market, including firm $j$, is $\sum_{k} \beta_{i k} \pi_{k}$, where $\beta_{i k}$ is owner $i$ 's equity stake (cash flow rights) in firm $k$ and $\pi_{k}$ is firm $k$ 's profit. Manager $j$ chooses output to maximize the weighted sum of this term across all owners $i$ of firm $j, \sum_{i} \gamma_{i j} \sum_{k} \beta_{i k} \pi_{k}$, where the weights, $\gamma_{i j}$, are the control rights that owner $i$ has in firm $j{ }^{8}$ The common ownership term derived from this maximization problem equals:

$$
H H I \Delta=\sum_{j} \sum_{k \neq j} \underbrace{\left(\frac{\sum_{i} \gamma_{i j} \beta_{i k}}{\sum_{i} \gamma_{i j} \beta_{i j}}\right)}_{\text {Ownership and Control }} \cdot \underbrace{s_{j} \cdot s_{k}}_{\text {Market Shares }} .
$$

Intuitively, owner $i$ 's common ownership in carriers $j$ and $k$ is captured by the term $\frac{\sum_{i} \gamma_{i j} \beta_{i k}}{\sum_{i} \gamma_{i j} \beta_{i j}}$. Owner $i$ 's control rights in carrier $j, \gamma_{i j}$, are measured as the number of shares that owner $i$ votes in carrier $j$ 's annual shareholders meeting. Owner $i$ 's cash flow right in carrier $j, \beta_{i j}$, is measured as the number of shares owner $i$ owns in carrier $j$. Both $\gamma_{i j}$ and $\beta_{i j}$ are expressed as a fraction of the total shares outstanding. ${ }^{9,10}$ The numerator captures the idea that if owner $i$ has control rights

\footnotetext{
${ }^{7}$ Common ownership (an investor owning shares in two or more competitors) is not the same as cross ownership (a firm holding a large financial equity stake in a product-market rival firm), and we refer to Kennedy et al. (2017) and Rock and Rubinfeld (2017), among others, for a discussion on the theoretical extrapolation AST make. We will focus on the empirical implementation of HHI $\Delta$ and its use in pricing regressions.

${ }^{8}$ From Bresnahan and Salop (1986) and O'Brien and Salop (2000), formally the objective function is given by: $\max _{x_{j}}=\sum_{i} \gamma_{i j} \sum_{k} \beta_{i k} \pi_{k}$ where the choice variable, $x_{j}$, is quantity. Additional details on the construction of $H H I \Delta$ can be found in Appendix I.

${ }^{9}$ If $\sum_{i} \gamma_{i j} \beta_{i j}=0$, we drop the term from the summation.

${ }^{10}$ We will return to the distinction between voting and cash flow rights in Section V.A.2.
} 
in firm $j$ and cash-flow rights to firm $k, \gamma_{i j}>0$ and $\beta_{i k}>0$ with $k \neq j$, then owner $i$ will use her control rights in firm $j$ to make $j$ compete less aggressively with firm $k$, thus increasing $H H I \Delta$, and ultimately allowing $j$ and $k$ to increase prices in the markets they serve. The denominator captures how this effect is attenuated when owner $i$ has both ownership and control rights in firm $j, \gamma_{i j}>0$ and $\beta_{i j}>0$, as $H H I \Delta$ decreases in $\gamma_{i j} \beta_{i j}$.

AST's main econometric specification is a fixed effects regression of the logarithm of the average airfare charged by carrier $j$ on route $r$ during year-quarter $t$, on the measure of common ownership, $H H I \Delta_{r t}$, the traditional Herfindahl Index, $H H I_{r t}$, a set of control variables, year-quarter fixed effects, and market-carrier fixed effects:

$$
\log \left(p_{r j t}\right)=\alpha \cdot H H I \Delta_{r t}+\eta \cdot H H I_{r t}+\theta \cdot X_{r j t}+\alpha_{t}+\nu_{r j}+\varepsilon_{r j t}
$$

where $p_{r j t}$ is the average ticket price for airline $j$, in market $r$, in year-quarter $t$; industry concentration in route $r$ at time $t$ is captured by $H H I_{r t}$; and the additional effect on concentration arising from common ownership is captured by $H H I \Delta_{r t}$. AST cluster standard errors in two ways, by market-carrier and by year-quarter. An important feature of AST's estimation is that all regressions are weighted by "the average number of passengers for the market and carrier over time." We explore the issue of weighting in Section V.B.

In addition, AST also estimate the following market-level regressions:

$$
\log \left(p_{r t}\right)=\beta \cdot H H I \Delta_{r t}+\gamma \cdot H H I_{r t}+\theta \cdot X_{r t}+\alpha_{t}+\nu_{r}+\varepsilon_{r t}
$$

where $p_{r t}$ is the average price of a ticket fare for market $r$ at time $t$, across all carriers serving market $r$ at time $t$. Standard errors are clustered by market and year-quarter and regression weights are given by the average number of passengers in the market over time.

There are three separate regression specifications that AST report. The first includes yearquarter fixed effects and market-carrier fixed effects, but no other covariates. The second adds the logarithm of the distance between endpoint airports interacted with year-quarter fixed effects, "to control for the price effect of changes in oil or fuel prices that may differentially affect routes of different length in ways that could be correlated with common ownership for some reason" (page 
14, Section 5.1.1). The third regression adds some additional market characteristics as covariates including the number of carriers operating nonstop flights in the market, indicator variables for whether Southwest or another LCC operates a nonstop flight in the market, the share of passengers traveling with connections (at both the market-carrier and market level), the logarithm of the geometric mean of the population of the two endpoints cities in the market, and the log of the geometric mean of the per capita income in those two market-endpoint cities.

\section{B. Construction of the AST Dataset and Comparison of Summary Statistics}

AST have provided a replication kit on the website of the Journal of Finance that can be used to reproduce results in their paper. The kit includes their Stata code for filtering the raw data, conducting the empirical analysis, and creating the tables and figures in the paper. However, it does not include the two primary data sources used in the analysis. ${ }^{11}$ We obtained these two data sources and applied AST's code to reconstruct their estimation sample and replicate their main results on the relationship between common ownership and ticket prices.

The primary data source for airline data is the Department of Transportation's Airline Origin and Destination Survey (DB1B) database, which is maintained by the Bureau of Transportation Statistics (BTS). The DB1B is a quarterly, 10 percent random sample of domestic airline tickets. There are three different subcomponents of the DB1B - market data, coupon data, and ticket data - and AST combine variables from all three sources. ${ }^{12}$ Information in the DB1B includes itinerary fares, endpoint airports, passenger quantities, number of plane changes, fare class, and the identity of the ticketing and operating carrier. AST focus their empirical analysis on the time period 2001:Q1-2014:Q4.

AST supplement their DB1B data with information from three additional data sources. First, they use the BTS's T100 Segment database to calculate the total number of carriers operating nonstop flights in a market in a given quarter, and to identify whether Southwest Airlines or

\footnotetext{
${ }^{11}$ Institutional ownership data is from Thomson Reuters and is proprietary, while the airline data is publicly available.

${ }^{12}$ A "market," in this context, is a trip between the two endpoint airports of an itinerary. Itineraries with the same endpoint airports, but with travel in opposite directions are grouped together into the same market (i.e. a roundtrip itinerary from Atlanta to Boston that starts and ends in Atlanta is grouped with a roundtrip itinerary from Boston to Atlanta that starts and ends in Boston). A coupon identifies a segment of travel. For example, a one-way flight from Atlanta to Boston that stops in Chicago would correspond to the Atlanta-Boston market, but would have two coupons, ATLORD and ORDBOS.
} 
another low-cost carrier (LCC) operates nonstop flights in a market in a given quarter. ${ }^{13}$ Second, AST obtain income and population data from the Bureau of Economic Analysis (BEA) at the MSA-level, to construct the geometric means of endpoint populations and endpoint income per capita. We obtain similar data from the T100 and BEA and impose the same restrictions reported by AST when integrating into the DB1B sample. Third, AST obtain the number of shares each institution owns, as well as the voting rights associated with those shares, from the SEC 13F filings via the Thomson-Reuters institutional 13F holdings database. ${ }^{14}$ We also use this ownership and voting data to construct the additional market concentration due to common ownership, $H H I \Delta$.

Table I compares the sample summary statistics reported by AST with those of the dataset that we constructed. The columns labeled "AST Sample" are taken directly from Table II in the AST paper, while the columns labeled "DGS Sample" correspond to the dataset that we have built by applying AST's code to the airline and ownership data we obtained from the same sources. The table shows that the samples are not identical, but are very similar. Our observation counts are always within 500 observations of the AST counts, and the means and standard deviations of all variables are extremely close for both the market-carrier-level and market-level samples, respectively.

\section{Replication of AST Regression Analysis}

Table II, Panel A, reports results for market-carrier level regressions. Columns (1)-(3) display AST's estimates taken directly from Table III in their paper; and columns (4)-(6) report results using our reconstruction of the AST data sample and regression specifications. We replicate AST's results perfectly for $H H I \Delta$ in the base specification and to the second decimal in the more saturated specifications. In addition, the coefficient estimates associated with the control variables are broadly similar across the two analyses. Finally, the inclusion of the additional control variables (columns (3) and (6)) significantly reduces the HHI $\Delta$ coefficient by more than 30 percent in both analyses.

Panel B, reports results for the market-level regressions. Columns (1)-(3) again display AST's

\footnotetext{
${ }^{13}$ The T100 database is a monthly census of domestic, nonstop flight segments performed by both U.S. and foreign carriers. The information is reported by operating carriers rather than ticketing carriers. AST assume that a ticketing carrier in their sample competes nonstop in a market if it tickets at least one coupon in the DB1B dataset for which the operator carrier is operating nonstop in the market according to the T100 database. In addition, AST only assume that a carrier operated nonstop in a quarter if it performed at least 60 flights in each direction during the quarter. However, for LCCs, including Southwest, they drop the threshold to 24 flights per quarter in each direction.

${ }^{14} \mathrm{AST}$ complete missing data for a set of five institutions with data from the SEC, and we do so too.
} 
estimates taken directly from Table III in their paper, while columns (4)-(6) report our replication results. Though our results do not perfectly replicate AST's, the differences are fairly negligible ( 0.325 versus 0.323 for the base specification, and 0.202 versus 0.196 for the most saturated specification).

The regression results in Table II show that the HHI $\Delta$ coefficient is not just statistically significant, but economically large in magnitude: A one standard deviation increase in $H H I \Delta$ is correlated with higher mean prices, by 1.7 to 2.2 percent at the market carrier level, and by 2.2 to 3.6 percent at the market level. Furthermore, an increase in HHID from zero (no common ownership) to a level corresponding to the maximum amount of common ownership observed in the sample, is correlated with an increase in prices of 8.5 to 11.3 percent at the market-carrier level, and by 11.4 to 19.8 percent at the market level. AST interpret these results as causal effects of common ownership on airline ticket prices. We question such an interpretation and explore the nature of the relationship in the remainder of the paper.

\section{Sources of Identification}

Equation (1) shows that the measure of common ownership, HHID, is a function of both investor $i$ 's ownership and control in each carrier $j$ (cash flow rights, $\left(\beta_{i j}\right)$, and voting rights, $\left(\gamma_{i j}\right)$, respectively), as well as each carrier's market shares, $s_{j}$. To see how this can affect the pricing regression (equation (2)), we rewrite the equation as follows:

$$
\begin{aligned}
\log \left(p_{r j t}\right)= & \alpha \cdot \overbrace{\sum_{j} \sum_{k \neq j} \underbrace{\left(\frac{\sum_{i} \gamma_{i j t} \cdot \beta_{i k t}}{\sum_{i} \gamma_{i j t} \cdot \beta_{i j t}}\right)}_{\text {Ownership \& Control }} \underbrace{s_{r j t} \cdot s_{r k t}}_{\text {Market Shares }}}^{H H I \Delta}+\eta \cdot \overbrace{\sum_{j} \underbrace{s_{r j t}^{2}}_{\text {Market Shares }}}^{H H I} \\
& +\theta \cdot X_{r j t}+\alpha_{t}+\nu_{r j}+\varepsilon_{r j t} .
\end{aligned}
$$

There are two first-order concerns with this model, one econometric and one conceptual. The econometric concern with equation (4) is that it is a regression of prices on two functions of market shares. Since Weiss (1989), Bresnahan (1989), Schmalensee (1989), and Evans et al. (1993) the in- 
dustrial organization literature has recognized that market shares and prices are jointly determined in equilibrium, and therefore regression estimates of prices on market shares are biased. Alternative estimation techniques have been developed to address this bias; specifically for the airline pricing literature, Borenstein (1989) and Borenstein and Rose (1994) developed an instrumental variables approach that we apply in Section III.

The conceptual problem with equation (4) is that the measure of common ownership, HHI $\Delta$, includes both ownership and control terms as well as airline market shares. Because of the inclusion of market-carrier fixed effects $\left(\nu_{r j}\right)$, the $H H I \Delta$ coefficient, $\alpha$, is identified from time-series variation in average prices and common ownership. ${ }^{15}$ However, since the common ownership term is a mix of ownership and control with market shares, it is unclear whether $\alpha$ is being identified by the timeseries variation in the ownership and control components, or the time series variation in market shares. This distinction is important, because the widespread interpretation of the AST results is that increased common ownership by institutional investors increases airline ticket prices. If the results are instead driven by variation in airline market shares, then the policy implications are unclear. In this section we construct several placebo tests and show that it is the market share component of HHID that drives the identification and significance of this variable in the AST pricing regressions.

\section{A. What Identifies the HHID Coefficient?}

As we noted above, since the regression equations (2) and (3) include market-carrier and market fixed effects, respectively, the $H H I \Delta$ coefficient is being identified by the within market-carrier and within market time-series variation of average ticket prices and $H H I \Delta .{ }^{16}$ The within market-carrier (or within market) time-series variation in $H H I \Delta$ has two sources: First, time series fluctuations in investor $i$ 's ownership and control of the airlines serving a market; second, variation in airline $j$ 's market shares over time within a market. To disentangle these two sources of variation, we design a placebo test that involves constructing two new versions of $H H I \Delta$ :

1. Placebo Ownership, $H H I \Delta_{\text {True } M S}^{\text {Placebo }}$ Own: This measure eliminates the time-series variation in the common ownership term and retains the time-series variation in market shares.

\footnotetext{
${ }^{15}$ Since ownership and market shares both vary over time, the inclusion of the fixed effects means that identification comes from the time series variation in both ownership and market shares within the market carrier unit.

${ }^{16}$ Note that $H H I \Delta$ itself does not vary at the market-carrier level. It is constructed at the market level.
} 
2. Placebo Market Shares, HHI $\Delta_{\text {True Own }}^{\text {Placebo }}{ }^{M S}$ : This measure eliminates the time-series variation in market shares and retains the time-series variation in the common ownership term.

The placebo test involves re-estimation of equations (2) and (3) using these alternative measures of $H H I \Delta$. If the common ownership component of $H H I \Delta$ is driving the positive correlation with average prices, we would expect to find $H H I \Delta_{\text {True } M S}^{\text {Placebo }}$ Own $\approx 0$ and $H H I \Delta_{\text {True Own }}^{\text {Placebo }}>0$. In contrast, if the market shares component is driving the correlation between $H H I \Delta$ and prices then we would expect to find $H H I \Delta_{\text {True }}^{\text {Placebo }}$ Own $>0$ and $H H I \Delta_{\text {True Own }}^{\text {Placebo } M S} \approx 0$. We now turn to a more detailed discussion of how we construct our placebo HHI $\Delta$ measures and the results of these two exercises.

\section{B. Placebo Ownership and True Market Shares}

The placebo ownership measure needs to eliminate time-series variation in ownership and control while retaining variation in market shares. Since $H H I \Delta$ is a non-linear function of market shares and ownership and control shares, the particular level at which we fix ownership and control in the construction of $H H I \Delta_{\text {True }}^{\text {Placebo }}{ }_{\text {Own }}$ may affect the regression estimates. ${ }^{17}$ We address this concern by constructing multiple versions of $H H I \Delta_{\text {True } M S}^{\text {Placebo }}$ Own that fix the ownership and control component at different levels and show that the results are robust across the different measures.

Our first measure replaces the values of investor $i$ 's ownership $\left(\beta_{i j}\right)$ and control $\left(\gamma_{i j}\right)$ in carrier $j$ for all year-quarters in our sample with those observed for $i$ and $j$ in the first year-quarter of our sample period, 2001:Q1, generating $H H I \Delta_{\text {True } M S}^{2001: Q 1}$. This eliminates the time-series variation in the common ownership component of $H H I \Delta$ while retaining a realistic cross-sectional distribution of common ownership. We re-estimate equations (2) and (3) using HHI $\Delta_{\text {True } M S}^{2001: Q 1}$.

Next, we replace ownership and control for all year-quarters with those observed in 2001:Q2, generating $H H I \Delta_{\text {True } M S}^{2001: Q 2}$. We then use ownership and control for the following quarter in the sample. In total, we build 56 different measures, $H H I \Delta_{\text {True } M S}^{2001: Q 1}, H H I \Delta_{\text {True } M S}^{2014: Q 4}$, and estimate 56 separate market-carrier and market level regressions, one per placebo HHI $\Delta$.

Of the 56 quarters that we have in our sample, we selected a sub-sample of five equally spaced quarters (2001:Q1, 2004:Q2, 2007:Q4, 2011:Q1, and 2014:Q4), and display the detailed estimation

\footnotetext{
${ }^{17}$ This is similar to the way that marginal effects from non-linear discrete choice models are often sensitive to the particular levels of the covariates.
} 
results corresponding to those quarters in Table III. Panel A displays market-carrier level regression results while Panel B displays market level regression results. All regressions correspond to the most saturated AST specifications (columns (3) and (6) in Table II). While we observe some heterogeneity in the market-carrier level regression results, four out of the five placebo measures yield coefficient estimates that are positive and statistically significant. The market level regression results yield coefficient estimates that are all positive and statistically significant, varying in magnitude between 0.08 and 0.41 .

Figure 1 displays the point estimates for each of the 56 regressions, each associated with a placebo measure, $H H I \Delta_{\text {True } M S}^{2001: Q 1}, \ldots, H H I \Delta_{\text {True } M S}^{2014: Q 4}$, along with the associated $95 \%$ confidence intervals. Panel A shows market-carrier level results while Panel B reports market level results. These results are consistent with those displayed in Table III. The coefficient estimates are positive and statistically significant at the five percent level for the majority of the placebo measures in the market-carrier level regressions, while they are positive and statistically significant at the five percent level for all but five of the market level regressions. ${ }^{18}$

The results displayed in Table III and Figure 1 provide evidence that identification of the $H H I \Delta$ coefficient is not coming from time-series variation in the common ownership component of $H H I \Delta$. Replacing ownership and control data with time-invariant, placebo values yields positive and statistically significant $H H I \Delta$ coefficients.

To corroborate that indeed it is the market share component in HHI $\Delta$ that identifies this coefficient, we need to test whether using placebo market shares and true ownership, HHI $\Delta_{\text {True Own }}^{\text {Placebo }}$, yields an economically and statistically insignificant coefficient estimate.

\section{Placebo Market Shares and True Ownership}

The placebo market share measure needs to mute time-series variation in market shares while retaining the time series variation in the common ownership component of $H H I \Delta$. We build two measures of $H H I \Delta_{\text {True Own }}^{\text {Placebo }}$ MS that differ in the levels at which market shares are set.

First, for each market, we define $N_{M a x}$ as the maximum number of carriers that are present in that market over the course of the sample period. If a carrier has a positive market share in

\footnotetext{
${ }^{18}$ The mean of the 56 estimated coefficients for the market-carrier level regressions is 0.077 (standard error $=0.014$ ) and is significantly different from zero at the $1 \%$ level. Since the coefficients are serially correlated, we estimated the standard error by modeling the errors as an $\mathrm{AR}(1)$ process and using the Cochrane-Orcutt estimator.
} 
that market in a particular quarter, we set this carrier's market share to $\frac{1}{N_{\text {Max }}}$. If a carrier does not serve a market in a particular quarter, we keep its market share at 0 . This strategy mitigates time-series variation in market shares since, conditional on a carrier being in the market, its market share is constant through time.

Results are presented in columns (1)-(2) of Table IV. The coefficient estimate associated with $\mathrm{HHI} \Delta_{\text {True Own }}^{\text {Place } M S}$ is negative in both the market-carrier level regression (column (1)) and the market level regression (column (2)). The estimate is not statistically different from zero in column (1), but it is significant in column (2), implying that an increase in $H H I \Delta$ due to within market times-series variation in common ownership is associated with a decrease in average prices. ${ }^{19}$

Next, we construct a second version of HHI $\Delta_{\text {True Own }}^{\text {Placebo } M S}$, this time replacing a carrier's market share with 1 if the carrier serves the market in a particular quarter and 0 otherwise. ${ }^{20}$ Results are displayed in columns (3)-(4) of Table IV. The coefficient estimates associated with $H H I \Delta_{\text {True Own }}^{\text {Placeb }}$ OS are effectively 0 in both the market-carrier and market level regressions.

Taken together the results in Tables III and IV suggest that the positive relationship between average ticket prices and $H H I \Delta$ documented by AST is driven by within market, time-series variation in airline market shares rather than variation in the extent of common ownership in a market.

In the next section, we address the second concern with estimating equation (4): the endogeneity of market shares. This is an important issue since, as we have just shown, it is the market share component of HHID that identifies this coefficient. We will show that once we instrument for market shares, there is no significant relationship between common ownership and average prices.

\section{Endogeneity of Market Shares}

Equation (4) highlights the fact that AST's primary empirical specification is a regression of prices on two functions of market shares, the traditional Herfindahl Index, $H H I$, and the measure of additional concentration due to common ownership, HHI . This is problematic since a firm's

\footnotetext{
${ }^{19}$ In Table IV we use true data for market shares to construct the traditional Herfindhal Index, HHI, which continues to yield positive and significant coefficients.

${ }^{20}$ This can be viewed as a "model-free" measure of common ownership, as we are eliminating the market share weights that come out of the firm maximization problem in the Cournot model of competition used by O'Brien and Salop (2000) to derive $H H I \Delta$. We thank Daniel Ferreira for this suggestion.
} 
market share and the prices it charges are jointly determined in equilibrium. As Evans et al. (1993)

state:

"The OLS estimator of the effect of concentration on price is biased for two reasons.

First, performance feeds back into structure, causing a simultaneous equation bias.

Second, as a function of outputs or revenues, measured concentration is correlated with

determinants of price that are, at best, measured with error, so measured concentration

is correlated with the error term."

And the authors offer a solution:

"With panel data, fixed effects procedures can be combined with instrumental variables

to eliminate bias from both sources."

In this section we address the endogeneity problem in equation (4) by following the advice of Evans et al. (1993) and using a combination of fixed effects and instrumental variables. ${ }^{21}$ Note that equation (4) includes market-carrier fixed effects, $\nu_{r j}$, and year-quarter fixed effects, $\alpha_{t}$, which may alleviate some concerns about endogeneity bias. For example, $\nu_{r j}$ controls for time-invariant effects that a particular carrier $j$ flying in a particular market $r$ may have on the ticket pricing of that carrier in that market. ${ }^{22}$ Year-quarter fixed effects, $\alpha_{t}$, control for variation in prices that stem from exogenous, serially correlated, industry-specific shocks to demand (e.g., seasonal effects, trends in oil prices, etc.). Similar logic holds for the fixed effects included in equation (3) except that this is a market-level regression and therefore includes market fixed effects rather than market-carrier fixed effects. ${ }^{23}$

\footnotetext{
${ }^{21}$ See also Berry (2017) keynote address to the FTC: "Market Structure and Competition, Redux" https://www . ftc.gov/system/files/documents/public_events/1208143/22_-_steven_berry_keynote.pdf, accessed May 2019. And also, Bresnahan (1989), Weiss (1989), Schmalensee (1989).

${ }^{22} \mathrm{~A}$ carrier in a given market might fly more modern planes, or serve more business passengers than other airlines in that market, which would likely cause variation in average ticket prices in such markets. As long as these effects do not change significantly during our sample period, their impact on average prices will be absorbed by the market-carrier fixed effects. Similarly, these fixed effects absorb variation in prices that may be due to one of the endpoint airports in the market being a hub for a particular carrier. In addition, if there are sample selection issues that arise when the unobservable, time-invariant factors that affect a carrier's decision to enter a market are the same unobservable variables that influence a carrier's pricing decisions in that market, then market-carrier fixed effects account for these issues (see, for example, Nijman and Verbeek (1992) treatment of self-selection of firms into markets).

${ }^{23}$ If an institutional investor's decision to own shares in a firm is influenced by the average prices in the markets where that firm operates, then the ownership component of HHID in equation (2) might also raise endogeneity concerns. AST address this issue by creating an instrument based on variation in ownership caused by BlackRock's acquisition of Barclays Global Investors in 2009. AST do not mention or address the endogeneity of market shares in the pricing regressions. In this paper we focus precisely on the latter concern.
} 
While the fixed effects included in equation (2) (equation (3)) account for unobserved, timeinvariant, market-carrier (market) factors, as well as unobserved aggregate time varying industrylevel demand shocks, they do not address unobserved origin and destination time-varying factors that may be correlated with both average ticket prices and market concentration. Previous studies in the airline pricing literature have addressed this by including origin and destination time trends. These controls address endogeneity concerns stemming from persistent correlation in unobserved, time-varying demand shocks that affect endpoint airports and that may also affect ticket prices. ${ }^{24}$ For example, the Global Financial Crisis that began in 2008 affected the economies of some cities more than others (e.g., Detroit, Las Vegas), so flights in and out of airports in those cities may have experienced a drop in demand and lower average ticket prices as a result. This could generate a positive correlation between market shares and average prices, which in turn could induce a positive correlation between average prices and $H H I \Delta$ (i.e. through its market share component)

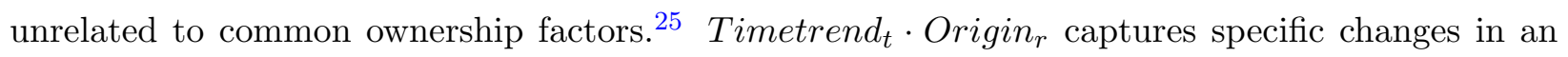
origin over time, where Origin $_{r}=1$ for the origin corresponding to market $r$ (and 0 otherwise) and Timetrend $_{t}$ is a year-quarter time trend variable, taking the values 1 (for 2001:Q1) to 52 (for 2014:Q4). We define Timetrend T Dest $_{r}$ in a similar manner to capture trends in a destination airport over time. Table V, which we discuss below, displays estimation results that include these time trends as additional controls.

The origin and destination time trends may help to alleviate some endogeneity bias, however they might not entirely mitigate this concern. To more fully address the endogeneity of market shares we turn to an instrumental variables analysis. The endogenous variable in equations (2) and (3) is market share, which enters in the calculation of both $H H I$ and $H H I \Delta$. Thus, we need to construct an instrument for market share, and use it to instrument for $H H I$ and $H H I \Delta$. To do so, we implement the two-part strategy developed by Borenstein (1989).

First, we generate plausibly exogenous market shares using airport shares. The underlying assumption is that an airline's market share for a particular route should be correlated with the strength of its overall presence at the endpoint airports (based on enplaned passenger counts),

\footnotetext{
${ }^{24}$ See Friedberg (1998) for a general discussion of the inclusion of time trends to proxy for unobserved time-varying factors. In the airline literature, see Ciliberto and Schenone (2012), Ciliberto, Cook, and Williams (2017), Aggarwal and Schenone (2019).

${ }^{25}$ If either the origin or destination is a hub airport for any carrier, these time trends will also absorb any trending hub effects.
} 
while its presence at the endpoint airports shouldn't directly impact average prices charged on a

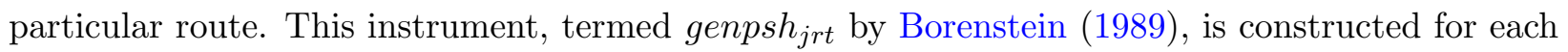
carrier $j$ as the ratio of $j$ 's geometric mean of the number of enplaned passengers at each endpoint of the route, to the sum across all carriers, $k$, of the geometric mean of each carrier's enplanements at the endpoint airports of the route. Let $E N P_{j t r_{1}}\left(E N P_{j t r_{2}}\right)$ be the total number of passengers enplaned by carrier $j$ at time $t$ at the endpoint $r_{1}\left(r_{2}\right)$ of route $r, g e n p s h_{j r t}=\frac{\sqrt{E N P_{j t r_{1}} \cdot E N P_{j t r_{2}}}}{\sum_{k} \sqrt{E N P_{k t r_{1}} \cdot E N P_{k t r_{2}}}}$.

Next, we regress market shares $s_{j r t}$ on genpsh $_{j r t}$ :

$$
s_{j r t}=\alpha_{I V}+\beta \cdot g e n p s h_{j r t}+\delta_{t} \cdot u_{t}+\eta_{j r t} .
$$

The fitted values of market shares, $\widehat{s_{j r t}}$, are the plausibly exogenous market shares used to construct instruments for $H H I$ and $H H I \Delta$. Specifically, to instrument for $H H I$, Borenstein (1989) uses irutherf $f_{j r t}:^{26,27}$

$$
\text { irutherf } f_{j r t}={\widehat{s_{j r t}}}^{2}+\frac{H H I_{r t}-s_{j r t}^{2}}{\left(1-s_{j r t}\right)^{2}} \cdot\left(1-\widehat{s_{j r t}}\right)^{2}
$$

To instrument for $H H I \Delta$ we use $\widehat{s_{j r t}}$, and compute:

$$
H H I \Delta_{I V}=\sum_{j} \sum_{k \neq j} \frac{\sum_{i} \gamma_{i j} \beta i k}{\sum_{i} \gamma_{i j} \beta i j} \cdot \widehat{s_{j r t}} \cdot \widehat{s_{k r t}} .
$$

Before describing the results, we note that to construct genpsh $h_{j t}$ it is necessary to merge the airline ticket, coupon, and market data (DB1B origin and destination survey) with the T100 Domestic Segment data that contains the data needed to calculate the number of enplaned passengers at each origin and destination airport. ${ }^{28}$ When merging these databases we lose some tickets as

\footnotetext{
${ }^{26}$ Borenstein (1989) argues that this is a valid instrument under the assumptions that (1) genpsh is a valid instrument for market share, and (2) the concentration of traffic on a route that is not transported by the observed carrier is exogenous with respect to the price of the observed carrier. The latter assumption implies that, for example, United's ticket fare between Denver (DEN) and Chicago (ORD) does not affect how passengers flying other carriers in the DEN-ORD route are split between these other carriers.

${ }^{27}$ We also build an instrument for the $H H I$ directly based on only the fitted values of market shares: $H H I_{r t}^{I V}=$ $\sum_{j} \widehat{s_{j r t}^{2}}$. The results are robust to using this instrument. Since the established literature uses irutherf $f_{j r t}$ we report results using this instrument. For other applications of this instrument, see, for example, and Borenstein and Rose (1994), Borenstein and Rose (1995), Borenstein and Rose (2003), Gerardi and Shapiro (2009).

${ }^{28}$ The T100 Domestic Segment data is a monthly census of all nonstop domestic flight segments performed by U.S. carriers and is also maintained by the BTS. It includes all non-stop flights and is often used in the literature to identify markets that are not served on a regular basis, or for which the number of seats offered and passengers enplaned falls below a minimum threshold.
} 
well as market-carrier observations. Our market-carrier-year-quarter sample falls from 1,209,791 to 938,358 , while our market-year-quarter sample falls from 255,173 to $189,648{ }^{29}$ We will show below that the AST results hold in this reduced sample.

Table V displays regression results that address the endogeneity of market shares. Panel A presents estimates for the market-carrier level regressions, and Panel B shows the results for the market level regressions. We start by showing how the results change when origin and destination time trends are included in the specification. In both panels, column (1) reports our replication of AST's most saturated specification, and column (2) adds origin and destination time trends to that specification. The addition of origin and destination time trends yields coefficient estimates for HHI $\Delta$ that are positive and statistically significant for both sets of regressions, however, the magnitude of the coefficients declines. In the market-carrier specification, the coefficient estimate drops by approximately one-third in magnitude (from 0.147 to 0.100 ), while for the market specification, the drop is less pronounced (from 0.196 to 0.175 ).

Before presenting the IV estimation results, in column (3) we re-estimate the specifications in column (2) for the smaller T100-DB1B merged sample, so that we can distinguish between differences that arise from changing the sample size and differences that arise from implementing the instrumental variables approach. The results are not sensitive to reducing the sample size. In fact, column (3) in both panels shows that they are slightly stronger in the T100-DB1B merged sample.

Results from the implementation of the instrumental variables approach are displayed in column (4). ${ }^{30}$ In both panels, we see that the coefficient estimates for $H H I \Delta$ decline in magnitude and become statistically insignificant when we instrument for market shares. In the market-carrier regressions the point estimate drops from a statistically significant value of 0.11 to a statistically insignificant value of 0.05 . The decline is even greater in the market level regressions as the $H H I \Delta$ coefficient estimate drops from a statistically significant value of 0.18 to a statistically insignificant value of $0.06 .^{31}$

\footnotetext{
${ }^{29}$ The DB1B database includes tickets with connections as well as direct, but not necessarily non-stop tickets (direct flights with a stop, but no plane change). The T100 reports only non-stop tickets. This is the reason for the reduced observations.

${ }^{30}$ First stage estimates can be found in Table A.I of the Online Appendix.

${ }^{31}$ The coefficient estimates of the other controls are very similar across the OLS and IV specifications (not displayed in the table but available upon request). For example, the presence of Southwest and other LCCs in a market reduces prices in those markets, and markets with higher income per capita and larger populations are correlated with
} 
In summary, we find that correcting for the endogeneity of market shares eliminates the statistically significant, positive relationship between average ticket prices and $H H I \Delta$. These results, in concert with those on the sources of identification in Section II, call into question the claims that common ownership in the airline industry causes anti-competitive pricing behavior.

\section{Aggregating Ownership to the Fund Family Level}

In this section we address the issue of aggregating cash flow and voting rights across funds in the same fund family. As Azar et al. (2018b) have pointed out, it is possible that not aggregating, or incorrectly aggregating, could introduce measurement error in the construction of $H H I \Delta$ that may cause attenuation bias. ${ }^{32}$

The question of whether and how ownership and control held by funds within a fund family should be aggregated is not immediately clear. In constructing $H H I \Delta$, AST aggregate shareholdings (ownership and control) at the "fund-family level to match the institutional feature of voting and governance at the family level, as well as fund families' incentives, which-consistent with the incentives of their investors - are determined primarily by the value of their total assets under management," (p. 1525). ${ }^{33}$

We show that whether we aggregate ownership and control across funds in a family, do not aggregate at all, or use an aggregation strategy different from AST's, the estimated relationship between $H H I \Delta$ and average ticket prices is not materially affected. This finding is consistent with our contention that it is the time series variation in market shares (and not in ownership) that identifies the coefficient on $H H I \Delta$, as once again we change the ownership component of $H H I \Delta$ and its coefficient estimate remains largely unchanged. We argue this is further evidence that the AST results are likely driven by spurious correlation-specifically, endogeneity bias due to the inclusion of market shares in $H H I \Delta$.

higher ticket prices. On the other hand, the effect of instrumenting on the traditional $H H I$ is very different in the market-carrier level regressions compared to the market level regressions. The $H H I$ coefficient falls to a statistically insignificant negative value in the IV regression reported in Panel A, but remains positive and statistically significant in the market level IV regression in Panel B.

${ }^{32}$ AST made this argument in a rebuttal to an early version of this paper, accessed June 17, 2019, https://papers . ssrn. com/sol3/papers. cfm?abstract_id=3168095.

${ }^{33}$ For example, Blackrock Advisors LLC and Blackrock Financial Management Inc. are funds in the Blackrock family; and AST sum the number of shares owned (ownership) and the number of shares voted (control) of these funds, and groups them under a common "Blackrock" umbrella. 
Attempting to aggregate funds to the fund-family level presents a conceptual issue and a measurement issue. Conceptually, aggregating votes across funds in a family would be appropriate if there are no dissenting votes within the fund family. From a measurement perspective, there is no clear way to identify which funds belong to the same fund family in the Thompson Reuters database.

The first issue is not too controversial. Though each fund manager retains the right to vote shares according to the fiduciary duties owed to investors in that fund, instances of dissenting votes are unusual, as most managers follow the recommendations provided by a dedicated "Engagement and Voting Governance Group," of the fund family (see for instance Lund (2018)). ${ }^{34,35}$ Identifying how each fund voted would require compiling fund-level voting data from N-PX forms. ${ }^{36}$ Given the large number of funds within a fund family, the large number of shareholders' and managers' proposals on which funds cast votes during annual meetings, the number of firms in our sample, and the number of annual meetings held by each firm within the sample period, analyzing the N-PX filings would be an enormous task. Since prior research shows most funds within a family coordinate their votes, it seems reasonable to assume funds within a fund-family vote unanimously.

The second issue, identifying funds that belong to the same fund-family in the TR database, is also a difficult task because there are no explicit fund-family identifiers. ${ }^{37}$ Without an explicit identifier, there is no systematic way to identify which funds belong to a given family. There is a 30 character field in the TR database that lists the name of each fund. This field can be used to aggregate funds with similar names, under the justification that similarly named funds are likely part of the same fund-family. This is the strategy used in the AST analysis, which we discuss in more detail below. However, funds with similar names might not be funds in the same fund family.

\footnotetext{
${ }^{34}$ Page 517: "At BlackRock in 2015, one of their funds did not vote along with the other funds in only 18 per 100,000 of shareholder proposals. Likewise, at Vanguard, only 6 out of 100,000 proposals featured a fund voting differently than its other funds. State Street also showed a low level of internal disagreement, voting inconsistently in 195 per 100,000 proposals. By contrast, Fidelity (which has only $16 \%$ of its equity invested in passive funds) had internal disagreement in 3,144 of 100,000 votes. (..)"

${ }^{35}$ There are instances of dissenting votes by funds within a fund family. For example, (1). Vanguard Specialized Funds voted for, while Vanguard Index Fund voted against, proposals 1-3 concerning the merger between CVS and Caremark Rx, Inc. (CVS annual shareholder meeting March, 2007); (2). BlackRock Funds voted against, while BlackRock Natural Resources Trust voted for, the full slate of directors for Agnico Eagle Mines Limited (April 2017). These funds also casted dissenting votes during shareholder meetings for El Dorado Gold Corp. (April 2017) and Rio Tinto Plc. (June 2017).

${ }^{36}$ By August 31st of each year, mutual funds and other registered management investment companies must disclose, in the SEC's Form N-PX, each funds proxy voting record for the most recent 12-month period ending June 30.

${ }^{37}$ There are fund manager identifiers, which we (and AST) use to aggregate shareholdings up to the manager level.
} 
For example, two fund names in our sample, "State Street Research and Management Co." and "State Street Corp." share the words State Street, so one might be inclined to group them into a "State Street" family. However, the former fund belonged to MetLife Inc. and was never part of "State Street Corporation." To complicate things even further, MetLife Inc. sold "State Street Research and Management Co." to BlackRock on August 26, 2004. Therefore, shares owned by "State Street Research and Management Co." should not be aggregated with shares from "State Street Corporation" at any point in time, but in fact, should be aggregated with shares from BlackRock funds after 2004 .

To determine how robust the results are to various aggregation assumptions, we compute $H H I \Delta$ using three different aggregation methods. First, we use AST's aggregation strategy. While the authors do not provide details on their aggregation algorithm in the paper, an examination of their fund-to-fund-family mapping provided in the replication kit suggests that they use the name field in the TR database to group funds that appear to have similar names into the same fund family. ${ }^{38}$ Second, we do not aggregate, and treat each fund as an independent entity. Finally, we devise our own aggregation algorithm, which is also based on the fund name variable in the TR database. Specifically, for each year in our sample period, we select the top 20 fund managers ranked by assets under management. We then take the union of these managers across the sample period. This results in a set of 36 unique managers. For each of these 36 managers, we select a reasonable keyword that is broad enough to identify all possible funds that may be in the same family, yet narrow enough to make the search manageable. Then we manually examine all funds that contain that keyword, and for each keyword, select the managers that are likely to be members of the same fund family. ${ }^{39}$

Table VI displays the results of these three different aggregation strategies. We show estimation results for both market-carrier level (Panel A) and market level (Panel B) regressions using AST's aggregation strategy (columns (1)-(3)), no aggregation (columns (4)-(6)), and our alternative aggregation strategy based on the formal algorithm described above (columns (7)-(9)). It is clear from Table VI that aggregation does not materially affect the $H H I \Delta$ coefficient estimate. Focusing on AST's most saturated specification (columns (3), (6), and (9)), moving from AST's aggregation

\footnotetext{
${ }^{38}$ AST provide an Excel file that contains, for some funds, annotations from web searches on fund names.

${ }^{39}$ Table A.III in the Online Appendix shows the results of applying this algorithm to the TR data.
} 
method to no aggregation decreases the HHI $\Delta$ coefficient by 0.001 in the most saturated marketcarrier level specification (columns (1) and (4), Panel A) and increases the coefficient by 0.004 in the most saturated market level specification (columns (1) and (4) Panel B). Finally, using our alternative aggregation strategy described above ("DGS Aggregation") also yields similar results, with the coefficient estimates increasing by trivial amounts.

The results in Table VI are not surprising given our analysis up to this point. We know from Section II that it is the time-series variation in the market share component of $H H I \Delta$ rather than variation in the common ownership component that identifies this coefficient. Thus, we should not expect the estimate to be sensitive to changing some of the ownership/control values while largely keeping the variation in market shares unchanged, and this is exactly what we find in Table VI.

\section{Fragility of the AST Results}

In this section we further analyze the robustness of the AST results to two specific data issues and an econometric concern. The first data issue is that investor $i$ 's cash flow and voting rights in airline $j$ ( $\beta_{i j}$ and $\gamma_{i j}$, respectively) are not reported in the SEC Form $13 \mathrm{~F}$ for the period during which carrier $j$ operates under bankruptcy protection. We adopt three strategies to deal with this. The first strategy carries the pre-bankruptcy equity shares forward through the bankruptcy quarters. This is the assumption used throughout the AST analysis, which implicitly assumes that shareholders retain ownership and control over the bankrupt carrier. The second strategy carries the post-bankruptcy equity shares backward through the bankruptcy quarters. This strategy assumes that the post-bankrupcty shareholders own and control the airline during the bankruptcy period. The third strategy sets ownership values to zero during bankruptcy periods reflecting the fact that shareholders of a bankrupt firm lose cash flow (and virtually all control) rights in the distressed firm (note that assuming that equity holder $i$ of bankrupt carrier $j$ has no cash flow rights sets $\beta_{i j}=0$, and thus the corresponding term in HHI $\Delta$ is eliminated regardless of what we assume for control of firm $j$ by owner $i$ ). Each strategy yields different values for $\gamma_{i j}$ and $\beta_{i j}$ in $H H I \Delta$. We show how the AST regression results change based on the treatment of missing values for ownership and control of a bankrupt firm.

The second data issue that we address is the interpretation of voting designations reported 
in the Thompson Reuters $13 \mathrm{~F}$ filings. Institutions that file Form $13 \mathrm{~F}$ with the SEC must report not only the number of shares over which they have investment discretion (cash flow rights), but also the voting rights associated with those shares, classifying them into three mutually exclusive categories: "sole," "shared," or "no" voting power. In their construction of HHID, AST assume that a fund retains voting rights when it reports either "sole" or "shared" rights. We argue that these classifications are ambiguous and somewhat arbitrary, and are not consistently reported across investment funds nor within a given fund over time. Furthermore, we show that the relationship between $H H I \Delta$ and average prices is sensitive to different assumptions regarding the mapping of voting designations into control rights.

Finally, we consider the robustness of the AST regression results to the inclusion of regression weights. We do not find an economic, or an econometric, argument that justifies using passenger counts as regression weights in the pricing equations. We show that the positive relationship between common ownership and average prices is significantly attenuated when regression weights are not employed.

\section{A. Data Issues}

\section{A.1. Ownership and Control of a Bankrupt Firm}

During the sample period considered by AST (2001-2014), several U.S. airlines operated while in bankruptcy. Table VII, reports a list of carriers that filed for Chapter 11 protection and the date each airline entered and emerged from bankruptcy.

In the U.S., it is the fiduciary duty of management to take actions that are in the interest of the firm's shareholders (creditors and other firm stakeholders are assumed to be able to protect themselves via contractual means; e.g., through mechanisms such as covenants and trade credit agreements). ${ }^{40}$ However, when a firm becomes insolvent, the fiduciary duties of management change. Based on case law, in particular the Ghewalla court, Silberglied (2015) states that "When

\footnotetext{
${ }^{40}$ See Silberglied (2015), page 188 and the citation to case law therein: "In many states, including Delaware, directors of a solvent corporation owe no fiduciary obligation to the corporations creditors. Courts in these states have rejected efforts to expand the fiduciary obligations of directors of solvent corporations to creditors, finding that a creditors rights are fixed by contract with the corporation. Delaware courts have emphasized that "creditors are usually better able to protect themselves than dispersed shareholders. Indeed, in Delaware, favoring a creditor over a stockholder of a solvent corporation (absent a legal obligation to do so) may constitute a breach of the directors fiduciary obligation.
} 
a corporation becomes insolvent, directors continue to owe a fiduciary duty to the corporation as a whole. However, unlike for a solvent corporation, what is in the best interests of an insolvent corporation might not be what is in the best interests of stockholders." Silberglied (2015) further notes that "[w]hen a corporation is insolvent ... its creditors take the place of the shareholders as the residual beneficiaries of any increase in value." Finally, he notes that whether the directors should act in the best interests of creditors or in the best interest of the firm probably makes little difference since the residual beneficiaries of a bankrupt firm are the creditors. ${ }^{41}$

Thus, equity holders of a firm that operates under Chapter 11 are residual claimants and retain little, if any, cash flow or control rights. And though shareholders may have some control since they can often continue to elect directors just as they can outside of bankruptcy, important aspects of control shift to creditors, with the most important being that secured creditors control access to the firm's cash, which gives them significant influence over the bankruptcy outcome.

If the firm restructures successfully and emerges from court protection as a solvent firm, the equity holders at the time the firm filed for bankruptcy might receive shares in the reorganized firm. To see if this is the case in our sample, we inspected the "Reorganization Plan" and the "Bankruptcy Disclosure Statement" of the carriers that operated under court protection during our sample period: American Airlines, Delta Airlines, Northwest Airlines, United Airlines, and US Airways. These documents state the equity claims that shareholders (termed "interests" in the documents) have as part of the Chapter 11 Bankruptcy Reorganization Plan. The documents also provide the "status" of the claimant as impaired or unimpaired and whether the claimant is deemed to reject or accept the Reorganization Plan. This allows us to determine whether equity holders received any allocation when the airlines emerged from bankruptcy protection. In all cases, except for American Airline's emergence from bankruptcy, equity holders had a recovery of zero percent, where deemed impaired, and their voting was deemed to reject the reorganization plan. In the case of American Airlines, only 3.5 percent of its newly issued post-bankruptcy shares were allocated to the pre-bankruptcy equity holders (which is a very diluted distribution to any single pre-bankruptcy shareholder). Table VII shows the distribution to interests for each bankrupt

\footnotetext{
${ }^{41}$ Whether the shift of fiduciary duties happens "in the zone of insolvency," that is, before the firm officially files for bankruptcy protection under Chapter 11 of the U.S. Bankruptcy Code, is a matter of debate after Delaware's ruling in the Gheewalla court. Becker and Stromberg (2012) show that when a firm is not yet under bankruptcy protection but it is close to insolvency, the duties are already owed to creditors (see, amongst others, Ayotte and Morrison (2009)).
} 
carrier, and the document, page, and reporting date from which the data were pulled. ${ }^{42}$

Despite the fact that equity holders lose cash flow rights in the insolvent firm (and that their control rights are virtually lost), the primary AST pricing regressions assume that pre-bankruptcy equity holders retain control during bankruptcy. Specifically, the authors state:

Holdings are not observed during bankruptcy periods. During the bankruptcies of American Airlines, Delta Airlines, Northwest Airlines, United Airlines, and US Airways, we repeat the last observed value for percentage of shares owned. (p. 10)

Holdings are not observed during bankruptcy based on our discussion above as existing equity holders have no claims to the firm while it operates under bankruptcy protection. We therefore believe it is more appropriate to set cash flow and control rights to zero for equity holders during the bankruptcy period. Alternatively, it might be that post-bankruptcy shareholders may exert some control in the firm during the bankruptcy period. This might be the case if the managers of the insolvent firm are able to anticipate the identity of the investors that will receive some equity distribution as part of the firm's reorganization plan, as well as the identity of investors who will buy new shares in the newly reorganized firm, and in expectation of their ownership in the firm, managers adhere to those investors' objectives during bankruptcy.

We now explore whether the AST results are sensitive to these different assumptions about the treatment of ownership and control during periods of bankruptcy. Specifically, we re-estimate equations (2) and (3) with an alternative measure of $H H I \Delta, H H I \Delta_{C t r l A f t e r}$, where we set cash flow and control rights of equity holders during the Chapter 11 time period equal to the value of ownership and control first observed upon the firm's emergence from bankruptcy. We then consider a second alternative, HHI $\Delta_{N o C t r l}$, where we set control and cash flow rights of equity holders during the time period in which the firm operates under bankruptcy court protection to zero.

Figure A.2 in the online appendix displays the distribution of $H H I \Delta$ under the three different assumptions of cash flow and control rights in bankruptcy. The figure shows that carrying the last observed ownership and control measure prior to bankruptcy forward throughout the bankruptcy

\footnotetext{
${ }^{42}$ For a sample of an 8-K distribution to interests, see an excerpt from United Airline's 8-K filing in the Online Appendix Figure A.1.
} 
period (black dot-dashed line) compared to carrying the first observed cash flow and control rights after emerging from bankruptcy backward throughout the bankruptcy period (green solid line) does not materially affect the distribution of $H H I \Delta$. These alternative assumptions change the ownership and control parameters in $H H I \Delta\left(\gamma_{i j} \mathrm{~s}\right.$ and $\left.\beta_{i j} \mathrm{~s}\right)$, but do not significantly affect the market share component. In contrast, the distribution changes when we assume zero ownership and control in bankruptcy (red dashed line). Specifically, this assumption sets $\gamma_{i j}=\beta_{i j}=0$ and, thus, significantly increases the number of markets with zero common ownership. In setting the ownership and control parameters to zero, the effective time-series variation in the market share component materially changes (since it enters the $H H I \Delta$ formula multiplicatively).

Table VIII displays the results of this exercise. Columns (1)-(3) report market-carrier regressions and columns (4)-(6) report market-level regressions. For ease of comparison, we report the AST results that carry pre-bankruptcy ownership and control throughout the bankruptcy years in columns (1) and (4). Comparing these AST results with those in columns (2) and (5) that correspond to the HHI $\Delta_{\text {CtrlAfter }}$, we see a decline in the magnitude of the coefficient estimate from 0.147 to 0.097 , for the market carrier level regression and from 0.197 to 0.159 for the market-level regressions. Both estimates retain their statistical significance. In contrast, the coefficient estimates corresponding to HHI $\Delta_{N o C t r l}$ (columns (3) and (6)) drop significantly in magnitude and lose their statistical significance. In the market carrier regressions the coefficient declines from 0.147 to 0.038 and in the market regressions from 0.197 to 0.069 .

In sum, the AST results are sensitive to the assumption of ownership and control of an insolvent firm. Assuming that equity holders lose cash flow rights while the firm operates in bankruptcy (regardless of whether they retain control or not), eliminates the positive relationship between average ticket prices and $H H I \Delta$.

\section{A.2. Mapping Voting Designation and Control Rights}

AST use an institutional owner's voting rights to proxy for the control that the owner may have over the airline manager who is making pricing decisions. Specifically, for each year-quarter, AST set institution $i$ 's control of carrier $j$ ( $\gamma_{i j}$ in the HHI $\Delta$ formula) equal to the the number of shares institution $i$ declares it has voting power for in carrier $j$, over the total number of shares carrier $j$ has outstanding. Thus, for each share an institution holds, the voting right associated with it must be 
identified. Institutions that file Form $13 \mathrm{~F}$ with the SEC must report not only the number of shares over which they have investment discretion (cash flow rights), but also the voting rights associated with those shares, classifying them into three mutually exclusive categories: "sole," "shared," or "no" voting power. In their construction of $H H I \Delta$, AST use this voting designation and assume that a fund retains voting rights when it reports either "sole" or "shared" rights. There are reasons to be skeptical of the accuracy of the voting designations reported on Form 13F, which we discuss in more detail below. As a result, we revisit AST's definition of control and check whether their results are sensitive to how voting rights are assigned.

Careful inspection of the voting rights field in the Thompson Reuters data reveals significant heterogeneity in how different funds report voting rights. Furthermore, even within a fund, there are inconsistencies in how the fund designates votes over time. For example, prior to September 2005, Vanguard Group, one of the largest mutual fund companies in the world, characterized all of the shares it owned as having sole voting rights. However, after September 2005, it has reported all shares owned as having no voting rights. This change was not prompted by any SEC rules change, but was simply a unilateral decision by the Vanguard Group. We examined voting designations for other large institutional investors and did not find significant changes in how these institutions designated voting authority in late 2005. Another example of inconsistencies by one of the largest funds in the world is State Street Corporation, which reported a mix of shares with, and without, sole voting rights prior to the first quarter of 2004, but over the remainder of our sample period it designated all shares owned as having sole voting authority (the reverse of Vanguard's switch). To illustrate these inconsistencies, Figure 2 plots, for a sub-sample of institutions in our data, the percent of shares designated with "sole", and those with "no" voting right (as a fraction of all shares owned) for each year-quarter observation in our sample. The volatility in voting designations reported across funds, and within a fund over time, is consistent with conversations that we had with SEC officials, who reported that the "Special Instruction 12.b.viii to Form 13F" voting designation guidelines are vague, and that reporting depends on how each institution interprets the guidelines; a statement confirmed by the corporate governance teams of two large asset management firms. ${ }^{43,44}$

\footnotetext{
${ }^{43}$ The guidelines can be found in the SEC website, https://www.sec.gov/about/forms/form13f.pdf

${ }^{44}$ Some institutions record sole voting power over routine matters (e.g., the selection of an accountant), as well as non-routine matters (e.g., a contested election of directors, or a merger approval); some report voting authority as "none" under a few different scenarios, including situations in which the shares have been lent to another institution for a short sale, or when shares are under sub-advisory contracts. In addition, institutions report no voting rights
} 
If institution $i$ 's voting rights captures $i$ 's control of firms in its portfolio, and control impacts how common ownership affects product market prices, then we might expect different assumptions about voting designations to affect the relationship between $H H I \Delta$ and ticket prices. For example, when Vanguard switched to designating all shares owned as having no voting rights, Vanguard's contribution to common ownership captured in $H H I \Delta$ by the term $\frac{\sum_{i} \gamma_{i j} \beta_{i k}}{\sum_{i} \gamma_{i j} \beta_{i j}}$, vanishes as $\gamma_{V a n g u a r d, j}$ becomes 0 for all carriers $j$ in Vanguard's portfolio. The opposite is true when State Street changed its designations in 2004, as $\gamma_{\text {StateStreet }, j}$ became positive for all carriers $j$ in State Street's portfolio. Furthermore, assumptions about how to treat shares that are reported to have "shared" voting rights may also materially affect the common ownership component of HHI (also through their impact on the $\gamma$ terms) and, thus, may affect the relationship between prices and $H H I \Delta$. To investigate this sensitivity we build two alternative versions of $H H I \Delta$ under different assumptions regarding the mapping of voting designations in the TR dataset to the parameter that governs the extent of investor control, $\gamma_{i j}$, in the $H H I \Delta$ formula.

First, we construct $H H I \Delta_{\text {Sole }}$, which assumes institution $i$ 's control rights are given by the number of shares the institution designates as having "sole" voting power (thus, unlike AST, we assume that investors reporting "shared" voting power do not exert control over the airline(s) it

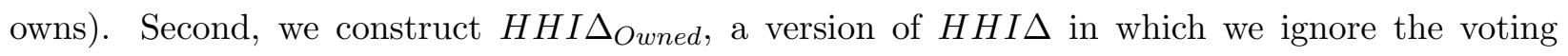
designations in the TR data and instead assume that investors hold voting power over all of the shares owned (thus, assuming that investors reporting "no" voting power, do retain some control over the airline). This alternative measure is motivated by our discussion above regarding the discrete change in how Vanguard and State Street reported their voting rights.

To examine this further, Table A.IV in the Online Appendix displays the identity of the top ten investors that report the highest percentage of shares owned designated as having " $n o$ " voting right during our sample period. In this list we find large institutional investors, such as Fidelity, T. Rowe Price, Vanguard, and Wellington. For example, over the entire 2001-2014 period, Fidelity reports no voting rights on over 90 percent of all airline shares owned, and Vanguard reports no voting rights for over 70 percent of the shares they own (after 2005, this percentage increases to

when, for example, a socially responsible investor delegates investment discretion and routine voting matters to an institution, but wishes to retain the voting rights on non-routine matters for the purpose of voting in a manner consistent with the investor's stated social responsibility objectives. The designation "shared" voting authority remains unclear. 
100). This strikes us as an implausibly high fraction, and consistent with the anecdotes from SEC economists, as well as lawyers at the largest institutional investment firms, who claim the "shared," "no," and "sole" designations are arbitrary and ambiguous.

Table IX displays results from estimating equations (2) and (3) with these alternative measures of $H H I \Delta$. Columns (1)-(3) report market-carrier level regressions (equation (2)), and columns (4)-(6) report market level regressions (equation (3)). Results shown are for the most saturated regression specification. For ease of comparison, columns (1) and (4) report our replication of AST's results, columns (2) and (5) present results for $H H I \Delta_{\text {Sole }}$, and columns (3) and (6) for HHI $\Delta_{\text {Owned }}$

Comparing columns (1) and (2), we see that the AST results are not sensitive to the treatment of voting rights reported to be "shared" in the construction of HHI $\Delta$ in the market-carrier specifications. The results are similar for the market-level regressions (columns (4) and (5)). However, the results are quite sensitive to the treatment of shares reported to have no voting rights. When

all shares are assumed to have voting rights (so that voting and control rights are equal), the HHI $\Delta$ coefficient drops from 0.147 to a statistically insignificant 0.044 in the market-carrier level regressions. In the market-level regressions the magnitude drops by almost 50 percent, from 0.196 to 0.104 , although the coefficient does remain statistically significant.

In summary, there are reasons to believe that reported voting rights in the TR database are poor proxies for control as they appear to be fairly arbitrary, even within a given institution over time, and estimates reported in Table IX show that the AST results are sensitive to voting designation assumptions.

\section{B. Econometric Issues: The Effect of Regression Weights}

Thus far we have provided empirical evidence showing that the primary AST results on the relationship between common ownership and average airline ticket prices are likely driven by endogeneity bias stemming from the inclusion of airline market shares in $H H I \Delta$ and, further, that it is variation in market shares, rather than ownership, that allows AST to identify the coefficient on $H H I \Delta$. In addition, we showed in the previous section that the results are sensitive to assumptions about ownership and control during bankruptcy periods and to assumptions about the mapping between reported voting designations and control. 
In this section we provide further evidence of the fragility of the results by showing that they are sensitive to the inclusion of regression weights. AST weight their regressions by passenger counts. Specifically, they state (p. 14):

Following Goolsbee and Syverson (2008), we weight the market-carrier level regressions by average passengers for the market and carrier over time.

With the exception of Goolsbee and Syverson (2008) (GS hereafter), the literature on airline pricing and market structure that uses the DB1B database does not employ regression weights (see for instance Borenstein (1989), Berry (1990), Borenstein and Rose (1994), Borenstein and Rose (2003), Gerardi and Shapiro (2009), Ciliberto and Schenone (2012), Snider and Williams (2015), and Ciliberto et al. (2017)). Other than citing GS's decision to weight by passenger counts, AST offer no additional reasoning for using regression weights in this context. ${ }^{45}$ According to Cameron and Triverdi (2008) (pages 112-115), Cameron and Triverdi (2010) (pages 821-829), and Solon, Haider, and Wooldridge (2015), there are typically three reasons for estimating weighted regressions. First, weights are necessary if there is a need to adjust the sample so that it is representative of the population. That is not the case here, as the DB1B is a random sample of all domestic airline tickets sold, and thus, is already a representative sample of such tickets. A second reason arises when using a stratified sample, with stratification based on the value of the dependent variable. Again, this is not the case with the DB1B sample. The third motivation for weighting is to correct for heteroskedastic error terms in order to obtain more precise estimation of causal effects. As discussed in Solon et al. (2015), one of the classic situations that calls for weighting is when the dependent variable in the analysis is a group average, and the averages for different groups are computed using highly varying, within-group sample sizes. In such a situation the group-average error term is heteroskedastic, and weighting by the square root of the number of individuals in each group yields efficient and consistent standard errors. ${ }^{46}$ Since employing a weighting strategy to address heteroskedasticity concerns requires a precise understanding of the nature of the heteroskedasticity,

\footnotetext{
${ }^{45}$ As justification for using passenger counts as weights, GS state (p. 1617) that doing so: "allows us to measure the 'aggregate' responses to Southwest's entry (and is particularly important when we look at passenger volume responses, because logged passenger numbers are particularly volatile on low-traffic routes)." However, since AST do not look at passenger volume responses in their analysis, it isn't immediately clear whether the GS rationale for including weights applies in this context.

${ }^{46}$ If this were the motivation behind AST's decision to estimate weighted regressions, the appropriate weights would be the square root of the number of itineraries over which average prices are calculated for a market-carrier quarterly observation.
} 
the vast majority of empirical researchers use White-Huber standard errors (also known as "heteroskedasticity robust" standard errors). The advantage of using White-Huber standard errors is they do not require assumptions about the structure of heteroskedasticity.

We explore how sensitive the AST results are to the inclusion of regression weights, and specifically re-estimate the pricing regressions without weights. Table $\mathrm{X}$ displays these results. We replicate the AST results for the most saturated regression specification in columns (1) and (3) at the market-carrier and market levels, respectively. Columns (2) and (4) display regression results with no weights. In the market-carrier regressions, the magnitude of the effect of $H H I \Delta$ on average fares declines by almost 70 percent from 0.147 to 0.045 . The results are not as sensitive to weighting in the market level regressions where the coefficient declines by almost 25 percent from 0.196 to 0.149 .

Table X shows that regression weights have a significant impact on the estimated coefficient of $H H I \Delta$, especially in the market-carrier level regressions. Intuitively, since the weights are based on passenger counts, their inclusion places more emphasis on the estimation of high-traffic markets. If the correlation between $H H I \Delta$ and average ticket prices is significantly stronger among high-traffic markets, then weighting regressions by passenger counts will produce larger coefficient estimates. We explore this issue further in Table XI, where we calculate various percentiles of the quarterly distributions of market-carrier passenger counts and market-level passenger counts. We focus on the median (p50), 75th percentile (p75), 90th percentile (p90), and 95th percentile (p95). We separately estimate the main AST specification for the sample of market-carrier observations (Panel A) and market observations (Panel B) that fall above and below each percentile. The results largely confirm our intuition: AST's estimated effect of common ownership on airline prices appears to be driven primarily by high-traffic routes. For the market-carrier level regressions, the effect is driven almost entirely by markets in the top decile of the passenger distribution. For the nearly 1.1 million observations below the 90th percentile of the passenger distribution, we find an economically small, marginally significant relationship between $H H I \Delta$ and average fares (column (6)). While the results are not as dramatic in the market-level regressions in Panel B, a similar pattern holds. The coefficient estimate of $H H I \Delta$ is more than twice as large in the markets above the 95 th percentile of the passenger distribution compared to those below the 95 th percentile $(0.316$ 
vs. 0.153$) \cdot{ }^{47}$

In summary, the estimated relationship between average prices and $H H I \Delta$ is sensitive to the inclusion of passenger counts as regression weights, especially the market-carrier specifications which are emphasized in the AST analysis. While AST do not provide a rationale for using the weights, one potential economic argument for doing so is that institutional investors may be more concerned with the most lucrative markets that yield the highest profits. Thus, investors may have a greater incentive to convince airline managers to engage in anti-competitive behavior in those markets. The concern is that the AST regression weights are based on passenger counts, not profits. More passengers may yield higher revenues, but not necessarily higher profits, specially if operating costs are also higher along the high-traffic routes.

\section{Conclusions}

This paper revisits the empirical evidence on the relationship between ticket prices and common ownership in the airline industry, as documented in Azar et al. (2018a). We find that the positive effect of common ownership on average airline prices is likely identified by variation in airline market shares rather than variation in institutional ownership. Further, it is driven by spurious correlation due to the inclusion of endogenous market shares in the measure of common ownership. Our findings complement the study of Kennedy et al. (2017), which also revisited the AST analysis and found little empirical evidence demonstrating the adverse effects of institutional ownership on the competitive structure of airline markets. Taken together, we believe that these two sets of results indicate the spurious nature of the Azar et al. (2018a) findings, and should be seriously considered by both legal scholars and policymakers who are currently contemplating regulations aimed at decreasing the extent of institutional ownership in product markets.

\footnotetext{
${ }^{47}$ Lack of variation in common ownership concentration among lower-trafficked markets is not generating these results. The standard deviation of the HHI $\Delta$ variable in the top fifth percentile of markets in the passenger count distribution is actually lower $(1,085)$ than the markets below the 95 th percentile $(1,184)$.
} 


\section{REFERENCES}

Aggarwal, Rajesh K., and Carola Schenone, 2019, Incentives and competition in the airline industry, Forthcoming, The Review of Corporate Finance Studies .

Ayotte, Ken, and E. Morrison, 2009, Creditor control and conflict in Chapter 11, Journal of Legal Analysis 1, 511-51.

Azar, José, Sahil Raina, and Martin C. Schmalz, 2016, Ultimate ownership and bank competition, University of Michigan manuscript.

Azar, José, Martin C Schmalz, and Isabel Tecu, 2018a, Anticompetitive effects of common ownership, Journal of Finance 73, 1513-1565.

Azar, José, Martin C Schmalz, and Isabel Tecu, 2018b, Reply to: "Common ownership does not have anti-competitive effects in the airline industry" .

Becker, Bo, and Per Stromberg, 2012, Fiduciary duties and equity-debtholder conflicts, The Review of Financial Studies 25, 1931-1969.

Berry, Steven, 1990, Airport presence as product differentiation, American Economic Review Papers and Proceedings 80, 394-399.

Borenstein, Severin, 1989, Hubs and high fares: Dominance and market power in the U.S. airline industry, RAND Journal of Economics 20, 344-365.

Borenstein, Severin, and Nancy Rose, 1994, Competition and price dispersion in the U.S. airline industry, Journal of Political Economy 102, 653-683.

Borenstein, Severin, and Nancy Rose, 1995, Bankruptcy and pricing behavior in the U.S. airline markets, American Economic Review Papers and Proceedings 85, 397-402.

Borenstein, Severin, and Nancy Rose, 2003, The impact of bankruptcy on airline service levels, American Economic Review Papers and Proceedings 93, 415-419.

Bresnahan, Timothy F., 1989, Empirical studies of industries with market powers, Handbook of Industrial Organization 2, 1011 - 1057. 
Bresnahan, Timothy F., and Steven C. Salop, 1986, Quantifying the competitive effects of production joint ventures, International Journal of Industrial Organization 4, 155-175.

Cameron, Colin A., and Pravkin K. Triverdi, 2008, Microeconometrics: Methods and Applications (Cambridge University Press).

Cameron, Colin A., and Pravkin K. Triverdi, 2010, Microeconometrics Using Stata (Stata Press).

Ciliberto, Federico, Emily E. Cook, and Jonathan W. Williams, 2017, Network structure and consolidation in the U.S. airline industry, 1990-2015, Review of Industrial Organization .

Ciliberto, Federico, and Carola Schenone, 2012, Bankruptcy and product-market competition: Evidence from the airline industry, The International Journal of Industrial Organization 20, 564-577.

Elhauge, Einer, 2015, Horizontal shareholding, Harvard Law Review 129, 1267-1317.

Evans, William N., Luke M. Froeb, and Gregory J. Werden, 1993, Endogeneity in the concentrationprice relationship: Causes, consequences, and cures, Journal of Industrial Economics 41, 431-38.

Friedberg, Leora, 1998, Did unilateral divorce raise divorce rates? Evidence from panel data, American Economic Review 88, 608-627.

Gerardi, Kristopher S., and Adam Hale Shapiro, 2009, Does competition reduce price dispersion? New evidence from the airline industry, Journal of Political Economy 117, 1-37.

Goolsbee, Austan, and Chad Syverson, 2008, How do incumbents respond to the threat of entry? Evidence from the major airlines, Quarterly Journal of Economics 123, 1611-1633.

Kennedy, Pauline, Daniel O’Brien, Minjae Song, and Keith Waehrer, 2017, The competitive effects of common ownership: Economic foundations and empirical evidence, Bates White Economic Consulting manuscript.

Lund, Dorothy S., 2018, The case against passive shareholder voting, Journal of Corporation Law $43,494-536$.

Nijman, Theo, and Marno Verbeek, 1992, Nonresponse in panel data: The impact on estimates of a life cycle consumption function, Journal of Applied Econometrics 7, 243-257. 
O'Brien, Daniel P., and Steven C. Salop, 2000, Competitive effects of partial ownership: Financial interest and corporate control, Antitrust Law Journal 54, 559-614.

Posner, Eric A., Fiona M. Scott Morton, and E. Glen Weyl, 2017, A proposal to limit the anticompetitive power of institutional investors, Antitrust Law Journal, forthcoming.

Rock, Edward B., and Daniel L. Rubinfeld, 2017, Defusing the antitrust threat to institutional investor involvement in corporate governance, Manuscript, New York University School of Law .

Schmalensee, Richard Lee, 1989, Inter-industry studies of structure and performance, Handbook of Industrial Organization 2, 1011 - 1057.

Silberglied, Russell C., 2015, Litigating fiduciary duty claims in bankruptcy court and beyond: Theory and practical considerations in an evolving environment, MIT Press 10, $181-216$.

Snider, Connan, and Jonathan Williams, 2015, Barriers to entry in the airline industry: A multidimensional regression-discontinuity analysis of AIR-21, Review of Economics and Statistics 97, $2897-2929$.

Solon, Gary, Steven J. Haider, and Jeffrey M. Wooldridge, 2015, What are we weighting for?, Journal of Human Resources 50, 301-316.

Weiss, Leonard W., 1989, Concentration and price, MIT Press . 


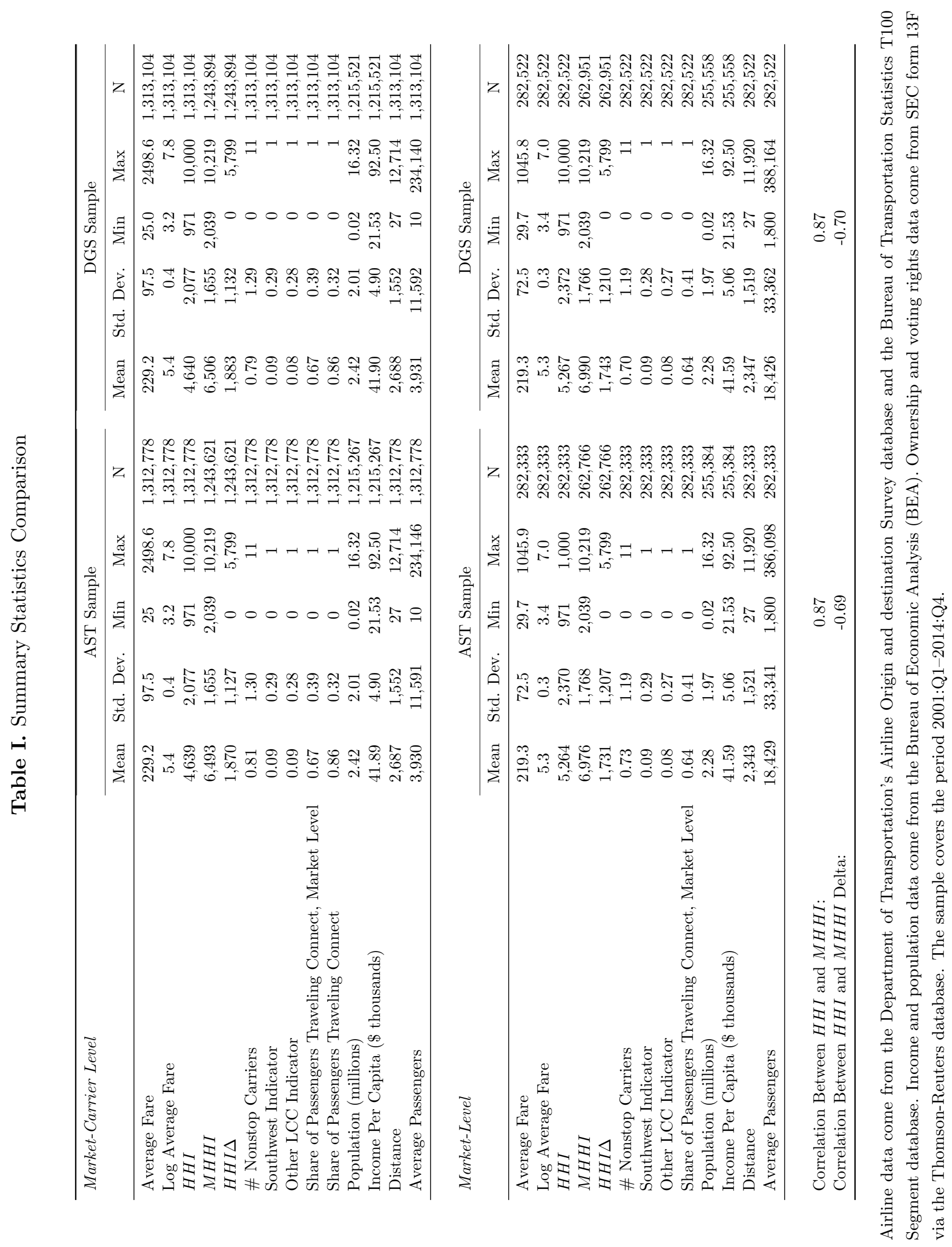


Table II. Replicating AST Results

Panel A: Market-Carrier Level Regressions

\begin{tabular}{|c|c|c|c|c|c|c|}
\hline & \multicolumn{3}{|c|}{$\mathrm{AST}$} & \multicolumn{3}{|c|}{ DGS } \\
\hline & $(1)$ & $(2)$ & $(3)$ & $(4)$ & $(5)$ & $(6)$ \\
\hline$H H I \Delta$ & $\begin{array}{c}0.194^{* * *} \\
(0.0459)\end{array}$ & $\begin{array}{c}0.219^{* * *} \\
(0.0387)\end{array}$ & $\begin{array}{c}0.149 * * * \\
(0.0375)\end{array}$ & $\begin{array}{c}0.194^{* * *} \\
(0.0463)\end{array}$ & $\begin{array}{c}0.218^{* * *} \\
(0.0392)\end{array}$ & $\begin{array}{c}0.147^{* * *} \\
(0.0380)\end{array}$ \\
\hline$H H I$ & $\begin{array}{c}0.221^{* * *} \\
(0.0247)\end{array}$ & $\begin{array}{c}0.230^{* * *} \\
(0.0246)\end{array}$ & $\begin{array}{c}0.165^{* * *} \\
(0.0209)\end{array}$ & $\begin{array}{c}0.222^{* * *} \\
(0.0248)\end{array}$ & $\begin{array}{c}0.230^{* * *} \\
(0.0249)\end{array}$ & $\begin{array}{c}0.163^{* * *} \\
(0.0211)\end{array}$ \\
\hline Number of Nonstop Carriers & & & $\begin{array}{c}-0.00979^{* * *} \\
(0.00269)\end{array}$ & & & $\begin{array}{c}-0.0105^{* * *} \\
(0.00264)\end{array}$ \\
\hline Southwest Indicator & & & $\begin{array}{r}-0.120^{* * *} \\
(0.00928)\end{array}$ & & & $\begin{array}{r}-0.119^{* * *} \\
(0.00930)\end{array}$ \\
\hline Other LCC Indicator & & & $\begin{array}{c}-0.0618^{* * *} \\
(0.00717)\end{array}$ & & & $\begin{array}{c}-0.0595^{* * *} \\
(0.00733)\end{array}$ \\
\hline $\begin{array}{l}\text { Share of Passengers } \\
\text { Traveling Connect, Market-Level }\end{array}$ & & & $\begin{array}{c}0.124^{* * *} \\
(0.0167)\end{array}$ & & & $\begin{array}{c}0.123^{* * *} \\
(0.0169)\end{array}$ \\
\hline $\begin{array}{l}\text { Share of Passengers } \\
\text { Traveling Connect }\end{array}$ & & & $\begin{array}{c}0.0986^{* * *} \\
(0.0143)\end{array}$ & & & $\begin{array}{c}0.105^{* * *} \\
(0.0139)\end{array}$ \\
\hline $\log ($ Population $)$ & & & $\begin{array}{c}0.306^{* * *} \\
(0.106)\end{array}$ & & & $\begin{array}{c}0.306^{* * *} \\
(0.106)\end{array}$ \\
\hline Log(Income Per Capita) & & & $\begin{array}{c}0.374^{* * *} \\
(0.102)\end{array}$ & & & $\begin{array}{c}0.370^{* * *} \\
(0.103)\end{array}$ \\
\hline $\log ($ Distance $) \cdot$ Yr-Qtr FE & & $\mathrm{x}$ & $\mathrm{x}$ & & $\mathrm{x}$ & $\mathrm{x}$ \\
\hline Yr-Qtr FE & $\mathrm{x}$ & $\mathrm{x}$ & $\mathrm{x}$ & $\mathrm{x}$ & $\mathrm{x}$ & $\mathrm{x}$ \\
\hline Market-Carrier FE & $\mathrm{x}$ & $\mathrm{x}$ & $\mathrm{x}$ & $\mathrm{x}$ & $\mathrm{x}$ & $\mathrm{x}$ \\
\hline \# Observations & $1,237,584$ & $1,237,584$ & $1,237,584$ & $1,237,878$ & $1,237,878$ & $1,209,791$ \\
\hline $\mathrm{R}^{2}$ & 0.82 & 0.83 & 0.84 & 0.82 & 0.83 & 0.84 \\
\hline \# Market-Carriers & 46,513 & 46,513 & 46,513 & 46,510 & 46,510 & 45,244 \\
\hline
\end{tabular}

Continued on next page 
Table II: Replicating AST Results (continued)

\begin{tabular}{|c|c|c|c|c|c|c|}
\hline & \multicolumn{6}{|c|}{ Panel B: Market Level Regressions } \\
\hline & \multicolumn{3}{|c|}{ AST } & \multicolumn{3}{|c|}{ DGS } \\
\hline & $(1)$ & $(2)$ & $(3)$ & $(4)$ & $(5)$ & $(6)$ \\
\hline$H H I \Delta$ & $\begin{array}{l}0.325^{* * *} \\
(0.0446)\end{array}$ & $\begin{array}{c}0.311^{* * *} \\
(0.0397)\end{array}$ & $\begin{array}{c}0.202^{* * *} \\
(0.0356)\end{array}$ & $\begin{array}{l}0.323^{* * *} \\
(0.0451)\end{array}$ & $\begin{array}{c}0.342^{* * *} \\
(0.0408)\end{array}$ & $\begin{array}{c}0.196^{* * *} \\
(0.0360)\end{array}$ \\
\hline$H H I$ & $\begin{array}{c}0.365^{* * *} \\
(0.0315)\end{array}$ & $\begin{array}{c}0.357^{* * *} \\
(0.0313)\end{array}$ & $\begin{array}{c}0.256^{* * *} \\
(0.0244)\end{array}$ & $\begin{array}{r}0.365^{* * *} \\
(0.0317)\end{array}$ & $\begin{array}{c}0.364^{* * *} \\
(0.0324)\end{array}$ & $\begin{array}{r}0.255^{* * *} \\
(0.0247)\end{array}$ \\
\hline Number of Nonstop Carriers & & & $\begin{array}{l}-0.0081^{* *} \\
(0.00371)\end{array}$ & & & $\begin{array}{r}-0.00825^{* *} \\
(0.00353)\end{array}$ \\
\hline Southwest Indicator & & & $\begin{array}{c}-0.149^{* * *} \\
(0.0135)\end{array}$ & & & $\begin{array}{c}-0.150^{* * *} \\
(0.0135)\end{array}$ \\
\hline Other LCC Indicator & & & $\begin{array}{r}-0.100^{* * *} \\
(0.00989)\end{array}$ & & & $\begin{array}{r}-0.101^{* * *} \\
(0.00992)\end{array}$ \\
\hline $\begin{array}{l}\text { Share of Passengers } \\
\text { Traveling Connect, Market-Level }\end{array}$ & & & $\begin{array}{c}0.158^{* * *} \\
(0.0189)\end{array}$ & & & $\begin{array}{c}0.179^{* * *} \\
(0.0192)\end{array}$ \\
\hline Log(Population) & & & $\begin{array}{c}0.343^{* * *} \\
(0.122)\end{array}$ & & & $\begin{array}{c}0.354^{* * *} \\
(0.122)\end{array}$ \\
\hline Log(Income Per Capita) & & & $\begin{array}{c}0.304^{* * *} \\
(0.110)\end{array}$ & & & $\begin{array}{c}0.318^{* * *} \\
(0.109)\end{array}$ \\
\hline Log(Distance $) \cdot$ Yr-Qtr FE & & $\mathrm{x}$ & $\mathrm{x}$ & & $\mathrm{x}$ & $\mathrm{x}$ \\
\hline Yr-Qtr FE & $\mathrm{x}$ & $\mathrm{x}$ & $\mathrm{x}$ & $\mathrm{x}$ & $\mathrm{x}$ & $\mathrm{x}$ \\
\hline Market FE & $\mathrm{x}$ & $\mathrm{x}$ & $\mathrm{x}$ & $\mathrm{x}$ & $\mathrm{x}$ & $\mathrm{x}$ \\
\hline $\begin{array}{l}\text { \# Observations } \\
\mathrm{R}^{2} \\
\# \text { Markets }\end{array}$ & $\begin{array}{c}262,350 \\
0.85 \\
7,185\end{array}$ & $\begin{array}{c}262,350 \\
0.86 \\
7,185\end{array}$ & $\begin{array}{c}254,900 \\
0.88 \\
6,906\end{array}$ & $\begin{array}{c}262,534 \\
0.85 \\
7,190\end{array}$ & $\begin{array}{c}262,534 \\
0.86 \\
7,190\end{array}$ & $\begin{array}{c}255,173 \\
0.88 \\
6,911\end{array}$ \\
\hline
\end{tabular}

Panel A reproduces the reported estimates for market-carrier level regressions reported in AST's Table III, columns (1)-(3). Our replication of those results are shown in columns (4)-(6). The regression equation is:

$$
\log \left(p_{r j t}\right)=\beta \cdot H H I \Delta_{r t}+\gamma \cdot H H I_{r t}+\theta \cdot X_{r j t}+\alpha_{t}+\nu_{r j}+\varepsilon_{r j t}
$$

Panel B reproduces the reported estimates for market-level regressions reported in AST's Table III, in columns (1)-(3). Our replication of those results are shown in columns (4)-(6). The regression equation is:

$$
\log \left(p_{r t}\right)=\beta \cdot H H I \Delta_{r t}+\gamma \cdot H H I_{r t}+\theta \cdot X_{r t}+\alpha_{t}+\nu_{r}+\varepsilon_{r t}
$$

For both models, $\log \left(p_{r j t}\right)$ is the logarithm of the average ticket fare of airline $j$ in market $r$ in year-quarter $t, H H I_{r t}$ is the traditional Herfindahl Index, $H H I \Delta_{r t}$ is the additional concentration due to common owners, $X_{r j t}$ is a set of control variables. All regressions are weighted by the average passengers for the market-carrier over time. The sample covers the period 2001:Q1 to 2014:Q4. Both equations include year-quarter fixed effects. Panel A includes market-carrier fixed effects. Panel B includes market fixed effects. Standard errors, clustered by year-quarter and market-carrier (Panel A) and market (Panel B), are reported in parentheses. Significance at the 1\%, 5\% and 10\% level is shown by $* * *, * *$, and $*$, respectively. 
Table III. Identification: True Market Shares and Placebo Ownership

\begin{tabular}{lccccc}
\hline \multicolumn{7}{c}{ Panel A: Market-Carrier Level Regressions } \\
\hline Sample: & $2001: \mathrm{Q} 1$ & $2004: \mathrm{Q} 2$ & $2007: \mathrm{Q} 4$ & $2011: \mathrm{Q} 2$ & $2014: \mathrm{Q} 4$ \\
\cline { 2 - 6 } & $(1)$ & $(2)$ & $(3)$ & $(4)$ & $(5)$ \\
\hline HHI $\Delta_{\text {True } \text { M S }}^{\text {lacebn }}$ & $0.137^{* * *}$ & $0.089^{*}$ & $0.161^{* *}$ & 0.045 & $0.062^{*}$ \\
& $(0.035)$ & $(0.045)$ & $(0.072)$ & $(0.033)$ & $(0.032)$ \\
& & & & & \\
HHI & $0.154^{* * *}$ & $0.146^{* * *}$ & $0.150^{* * *}$ & $0.135^{* * *}$ & $0.135^{* * *}$ \\
& $(0.020)$ & $(0.021)$ & $(0.020)$ & $(0.019)$ & $(0.019)$ \\
\hline Log(Distance) · Year-Quarter FE & $\mathrm{x}$ & $\mathrm{x}$ & $\mathrm{x}$ & $\mathrm{x}$ & $\mathrm{x}$ \\
Full Set of Controls & $\mathrm{x}$ & $\mathrm{x}$ & $\mathrm{x}$ & $\mathrm{x}$ & $\mathrm{x}$ \\
Year-Quarter FE & $\mathrm{x}$ & $\mathrm{x}$ & $\mathrm{x}$ & $\mathrm{x}$ & $\mathrm{x}$ \\
Market-Carrier FE & $\mathrm{x}$ & $\mathrm{x}$ & $\mathrm{x}$ & $\mathrm{x}$ & $\mathrm{x}$ \\
Market FE & & & & & \\
\hline \# Observations & $1,209,791$ & $1,209,791$ & $1,209,791$ & $1,209,791$ & $1,209,791$ \\
$\mathrm{R}^{2}$ & 0.84 & 0.84 & 0.84 & 0.84 & 0.84 \\
\# Market-Carriers & 45,244 & 45,244 & 45,244 & 45,244 & 45,244 \\
\hline
\end{tabular}

Panel B: Market Level Regressions

\begin{tabular}{lccccc}
\hline Sample: & $2001: \mathrm{Q} 1$ & $2004: \mathrm{Q} 2$ & $2007: \mathrm{Q} 4$ & $2011: \mathrm{Q} 2$ & $2014: \mathrm{Q} 4$ \\
\cline { 2 - 6 } & $(1)$ & $(2)$ & $(3)$ & $(4)$ & $(5)$ \\
\hline HHI $\Delta_{\text {True } \text { PS } S}^{\text {Placebn }}$ & $0.212^{* * *}$ & $0.186^{* * *}$ & $0.409^{* * *}$ & $0.081^{* *}$ & $0.098^{* * *}$ \\
& $(0.041)$ & $(0.055)$ & $(0.095)$ & $(0.038)$ & $(0.035)$ \\
HHI & & & & & \\
& $0.248^{* * *}$ & $0.246^{* * *}$ & $0.266^{* * *}$ & $0.222^{* * *}$ & $0.219^{* * *}$ \\
& $(0.025)$ & $(0.026)$ & $(0.026)$ & $(0.023)$ & $(0.023)$ \\
\hline Log(Distance) · Year-Quarter FE & $\mathrm{x}$ & $\mathrm{x}$ & $\mathrm{x}$ & $\mathrm{x}$ & $\mathrm{x}$ \\
Full Set of Controls & $\mathrm{x}$ & $\mathrm{x}$ & $\mathrm{x}$ & $\mathrm{x}$ & $\mathrm{x}$ \\
Year-Quarter FE & $\mathrm{x}$ & $\mathrm{x}$ & $\mathrm{x}$ & $\mathrm{x}$ & $\mathrm{x}$ \\
Market-Carrier FE & $\mathrm{x}$ & $\mathrm{x}$ & $\mathrm{x}$ & $\mathrm{x}$ & $\mathrm{x}$ \\
Market FE & 255,173 & 255,173 & 255,173 & 255,173 & 255,173 \\
\hline \# Observations & 0.88 & 0.88 & 0.88 & 0.88 & 0.88 \\
$\mathrm{R}^{2}$ & 6,911 & 6,911 & 6,911 & 6,911 & 6,911 \\
\# Markets & & & & & \\
\hline
\end{tabular}

This table reports the first of two placebo tests aimed at disentangling the effect of ownership, $\sum_{j} \sum_{k \neq j}\left(\frac{\sum_{i} \gamma_{i j} \beta i k}{\sum_{i} \gamma_{j} \beta i j}\right)$ from that of market share, $s_{j} s_{k}$, in $H H I \Delta$. Here we show the estimates from using five versions of HHI $\Delta$ that use true market shares, and placebo ownership (and set ownership equal to control $\left(\gamma_{i j}=\beta i j\right.$ in $\left.H H I \Delta\right)$ ). Panel A reports estimates for market-carrier specifications; Panel B for market-level specifications. We use the fully saturated specifications. The first placebo result (Column (1)) takes ownership in the first year-quarter of the sample (2001, quarter 1), and carries this level of ownership throughout the entire sample period $\left(H H I \Delta_{T r u e}^{2001} Q 1\right.$ S $)$. Column (5) reports results from carrying ownership in the last year-quarter of the sample (2014, quarter 4) throughout the sample period. Column (3) reports results from carrying ownership in the mid year-quarter of the sample period, (2007, quarter 4). Columns (2) and (4) do the same for the first and third quartile of the year-quarter sample period. Robust standard errors, in parentheses, are clustered by year-quarter and by market-carrier (Panel A) and market (Panel B). Significance at the $1 \%, 5 \%$ and $10 \%$ level is shown by ${ }^{* * *},{ }^{* *}$ and $*$, respectively. 
Table IV. Identification: Placebo Market Shares and True Ownership

\begin{tabular}{|c|c|c|c|c|}
\hline & \multicolumn{2}{|c|}{ Set Market Shares to $\frac{1}{N_{M a x}}$} & \multicolumn{2}{|c|}{ Set Market Shares to 1} \\
\hline & Market-Carrier Level & Market-Level & Market-Carrier Level & Market-Level \\
\hline & (1) & $(2)$ & $(3)$ & $(4)$ \\
\hline$H H I \Delta_{\text {True Own }}^{\text {Placebo } M S}$ & $\begin{array}{l}-0.050 \\
(0.056)\end{array}$ & $\begin{array}{c}-0.144^{* *} \\
(0.064)\end{array}$ & $\begin{array}{c}-0.001 \\
(0.001)\end{array}$ & $\begin{array}{c}-0.002^{* *} \\
(0.001)\end{array}$ \\
\hline$H H I$ & $\begin{array}{c}0.121^{* * * *} \\
(0.018)\end{array}$ & $\begin{array}{c}0.190^{* * * *} \\
(0.022)\end{array}$ & $\begin{array}{c}0.121^{* * *} \\
(0.018)\end{array}$ & $\begin{array}{c}0.191^{* * *} \\
(0.022)\end{array}$ \\
\hline Log(Distance) $\cdot$ Yr-Qtr FE & $\mathrm{x}$ & $\mathrm{x}$ & $\mathrm{x}$ & $\mathrm{x}$ \\
\hline Full Set of Controls & $\mathrm{x}$ & $\mathrm{x}$ & $\mathrm{x}$ & $\mathrm{x}$ \\
\hline Year-Quarter FE & $\mathrm{x}$ & $\mathrm{x}$ & $\mathrm{x}$ & $\mathrm{x}$ \\
\hline Market-Carrier FE & $\mathrm{x}$ & & $\mathrm{x}$ & \\
\hline Market FE & & $\mathrm{x}$ & & $\mathrm{x}$ \\
\hline \# Observations & $1,209,791$ & 255,173 & $1,209,791$ & 255,173 \\
\hline $\mathrm{R}^{2}$ & 0.84 & 0.88 & 0.84 & 0.88 \\
\hline \# Market-Carriers & 45,244 & & 45,244 & \\
\hline \# Markets & & 6,911 & & 6,911 \\
\hline
\end{tabular}

This table reports the second of two placebo tests aimed at disentangling the effect of ownership, $\sum_{j} \sum_{k \neq j}\left(\frac{\sum_{i} \gamma_{i j} \beta i k}{\sum_{i} \gamma_{i j} \beta i j}\right)$ from that of market share, $s_{j} s_{k}$, in $H H I \Delta$. Here we show the estimates from two versions of $H H I \Delta$ that use placebo market shares and true ownership. The first placebo for market share, $H H I \Delta_{\text {True Own }}^{M S=1 / N_{\text {Max }}}$, is constructed as follows: For each market, define $N_{\text {Max }}$ equal to the maximum number of carriers that serve that market during the entire sample period. If a carrier has a positive market share in that market during any quarter, set this carrier's market share to $\frac{1}{N_{\text {Max }}}$; else keep its market share at 0. Estimates are reported in Columns (1) and (2). The second placebo, $H H I \Delta_{\text {True Own }}^{M S}$, replaces a carrier's market share with 1 if the carrier serves the market in a particular quarter, 0 otherwise. Estimates reported in Columns (3) and (4). Panel A reports estimates for market-carrier specifications; Panel B for market-level specifications. We use the saturated specifications. Robust standard errors, in parentheses, are clustered by year-quarter and by market-carrier (Columns (1) and (3)) and market (Columns (2) and (4)) . Significance at the $1 \%, 5 \%$ and $10 \%$ level is shown by ${ }^{* * *}, * *$ and $*$, respectively. 
Table V. Correcting for Endogeneity

\begin{tabular}{|c|c|c|c|c|}
\hline \multicolumn{5}{|c|}{ Panel A: Market-Carrier Level Regressions } \\
\hline & \multicolumn{3}{|c|}{ OLS Specification } & \multirow{3}{*}{$\begin{array}{c}\text { IV Specification } \\
\text { IV }\end{array}$} \\
\hline & Full $s$ & ample & IV Sample & \\
\hline & AST & Add: TT & OLS & \\
\hline & $(1)$ & $(2)$ & $(3)$ & $(4)$ \\
\hline$H H I \Delta$ & $\begin{array}{c}0.147^{* * *} \\
(0.038)\end{array}$ & $\begin{array}{c}0.100^{* * *} \\
(0.032)\end{array}$ & $\begin{array}{c}0.105^{* * *} \\
(0.033)\end{array}$ & $\begin{array}{c}0.049 \\
(0.084)\end{array}$ \\
\hline$H H I$ & $\begin{array}{c}0.163^{* * *} \\
(0.021)\end{array}$ & $\begin{array}{c}0.109 * * * \\
(0.017)\end{array}$ & $\begin{array}{c}0.107^{* * *} \\
(0.018)\end{array}$ & $\begin{array}{c}-0.092 \\
(0.071) \\
\end{array}$ \\
\hline Log(Distance $) \cdot$ Yr-Qtr FE & $\mathrm{x}$ & $\mathrm{x}$ & $\mathrm{x}$ & $\mathrm{x}$ \\
\hline Full Set Controls & $\mathrm{x}$ & $\mathrm{x}$ & $\mathrm{x}$ & $\mathrm{x}$ \\
\hline Year-Quarter FE & $\mathrm{x}$ & $\mathrm{x}$ & $\mathrm{x}$ & $\mathrm{x}$ \\
\hline Market-Carrier FE & $\mathrm{x}$ & $\mathrm{x}$ & $\mathrm{x}$ & $\mathrm{x}$ \\
\hline Origin $\cdot$ Time Trend & & $\mathrm{x}$ & $\mathrm{x}$ & $\mathrm{x}$ \\
\hline Destination · Time Trend & & $\mathrm{x}$ & $\mathrm{x}$ & $\mathrm{x}$ \\
\hline \# Observations & $1,209,791$ & $1,209,791$ & 938,358 & 938,358 \\
\hline $\mathrm{R}^{2}$ & 0.84 & 0.85 & 0.86 & \\
\hline \# Market-Carriers & 45,244 & 45,244 & 36,766 & 36,766 \\
\hline
\end{tabular}

Panel B: Market Level Regressions

\begin{tabular}{|c|c|c|c|c|}
\hline & \multicolumn{3}{|c|}{ OLS Specification } & \multirow{3}{*}{$\begin{array}{c}\text { IV Specification } \\
\text { IV }\end{array}$} \\
\hline & \multicolumn{2}{|c|}{ Full Sample } & \multirow{2}{*}{$\begin{array}{l}\text { IV Sample } \\
\text { OLS }\end{array}$} & \\
\hline & $\mathrm{AST}$ & Add: TT & & \\
\hline & $(1)$ & $(2)$ & $(3)$ & $(4)$ \\
\hline$H H I \Delta$ & $\begin{array}{c}0.196^{* * *} \\
(0.036)\end{array}$ & $\begin{array}{c}0.175^{* * *} \\
(0.031)\end{array}$ & $\begin{array}{c}0.181^{* * *} \\
(0.032)\end{array}$ & $\begin{array}{c}0.063 \\
(0.088)\end{array}$ \\
\hline$H H I$ & $\begin{array}{c}0.255^{* * *} \\
(0.025)\end{array}$ & $\begin{array}{c}0.217^{* * * *} \\
(0.022)\end{array}$ & $\begin{array}{c}0.228^{* * *} \\
(0.024) \\
\end{array}$ & $\begin{array}{c}0.225^{* * *} \\
(0.053)\end{array}$ \\
\hline Log(Distance) $\cdot$ Yr-Qtr FE & $\mathrm{x}$ & $\mathrm{x}$ & $\mathrm{x}$ & $\mathrm{x}$ \\
\hline Full Set Controls & $\mathrm{x}$ & $\mathrm{x}$ & $\mathrm{x}$ & $\mathrm{x}$ \\
\hline Year-Quarter FE & $\mathrm{x}$ & $\mathrm{x}$ & $\mathrm{x}$ & $\mathrm{x}$ \\
\hline Market FE & $\mathrm{x}$ & $\mathrm{x}$ & $\mathrm{x}$ & $\mathrm{x}$ \\
\hline Origin $\cdot$ Time Trend & & $\mathrm{x}$ & $\mathrm{x}$ & $\mathrm{x}$ \\
\hline Destination $\cdot$ Time Trend & & $\mathrm{x}$ & $\mathrm{x}$ & $\mathrm{x}$ \\
\hline \# Observations & 255,173 & 255,173 & 189,648 & 189,648 \\
\hline $\mathrm{R}^{2}$ & 0.88 & 0.90 & 0.90 & \\
\hline \# Markets & 6,911 & 6,911 & 6,286 & 6,286 \\
\hline
\end{tabular}

This table presents results from IV regressions that account for endogeneity of market shares. Market share for carrier $j$, in route $r$ at time $t$ is instrumented using genpsh $_{j r t}$, the geometric mean of the number of enplaned passengers at each end point of the market, divided by the sum across all carriers of the geometric mean of each carrier's enplanements at the end point airports of the market (Borenstein (1989)): genpsh $h_{j r t}=\frac{\sqrt{E N P_{j t r_{1}} \cdot E N P_{j t r_{2}}}}{\sum_{k} \sqrt{E N P_{k t r_{1}} \cdot E N P_{k t r_{2}}}}$.

The fitted values from regressing market shares on genpsh ${ }_{j r t}, \widehat{s^{2}{ }_{j r t}}$ are used as an input to construct the instrument for HHI, irutherf (derived by Borenstein (1989)): iruther $f_{j r t}={\widehat{s_{j r t}}}^{2}+\frac{H H I_{r t t}-s_{j r t}^{2}}{\left(1-s_{j r t}\right)^{2}} \cdot\left(1-\widehat{s_{j r t}}\right)^{2}$.

Further, $\widehat{s_{j r t}}$ is used as an input to build the instrument for $H H I \Delta: H H I \Delta_{I V}=\sum_{j} \sum_{k \neq j} \frac{\sum_{i} \gamma_{i j} \beta i k}{\sum_{i} \gamma_{i j} \beta i j} \widehat{s_{j r t}} \cdot \widehat{s_{k r t}}$.

Robust standard errors, in parentheses, are clustered by year-quarter and by market-carrier (Panel A) and market (Panel B). First stage estimates can be found in Table A.I of Online Appendix. 
Table VI. The Effect of Aggregating Ownership and Votes Across Funds within Fund Families

Panel A: Market-Carrier Level Regressions

\begin{tabular}{|c|c|c|c|c|c|c|c|c|c|}
\hline & \multicolumn{3}{|c|}{ AST Aggregation } & \multicolumn{3}{|c|}{ No Aggregation } & \multicolumn{3}{|c|}{ DGS Aggregation } \\
\hline & (1) & (2) & (3) & (4) & (5) & (6) & (7) & (8) & (9) \\
\hline$H H I \Delta$ & $\begin{array}{c}0.194^{* * *} \\
(0.046)\end{array}$ & $\begin{array}{c}0.218^{* * *} \\
(0.040)\end{array}$ & $\begin{array}{c}0.147^{* * *} \\
(0.038)\end{array}$ & $\begin{array}{c}0.212^{* * *} \\
(0.050)\end{array}$ & $\begin{array}{c}0.225^{* * *} \\
(0.042)\end{array}$ & $\begin{array}{c}0.146^{* * *} \\
(0.041)\end{array}$ & $\begin{array}{c}0.204^{* * *} \\
(0.046)\end{array}$ & $\begin{array}{c}0.230 * * * \\
(0.039)\end{array}$ & $\begin{array}{c}0.155^{* * *} \\
(0.038)\end{array}$ \\
\hline$H H I$ & $\begin{array}{c}0.222 * * * \\
(0.025)\end{array}$ & $\begin{array}{c}0.230 * * * \\
(0.025)\end{array}$ & $\begin{array}{c}0.163 * * * \\
(0.021)\end{array}$ & $\begin{array}{c}0.223^{* * *} \\
(0.025)\end{array}$ & $\begin{array}{c}0.229 * * * \\
(0.024)\end{array}$ & $\begin{array}{c}0.161 * * * \\
(0.021)\end{array}$ & $\begin{array}{c}0.223^{* * *} \\
(0.025)\end{array}$ & $\begin{array}{c}0.233^{* * *} \\
(0.025)\end{array}$ & $\begin{array}{c}0.165^{* * *} \\
(0.021)\end{array}$ \\
\hline $\log ($ Distance $) \cdot$ Yr-Qtr FE & & $\mathrm{x}$ & $\mathrm{x}$ & & $\mathrm{x}$ & $\mathrm{x}$ & & $\mathrm{x}$ & $\mathrm{x}$ \\
\hline Full Set of Controls & & & $\mathrm{x}$ & & & $\mathrm{x}$ & & & $\mathrm{x}$ \\
\hline Year-Quarter FE & $\mathrm{x}$ & $\mathrm{x}$ & $\mathrm{x}$ & $\mathrm{x}$ & $\mathrm{x}$ & $\mathrm{x}$ & $\mathrm{x}$ & $\mathrm{x}$ & $\mathrm{x}$ \\
\hline Market-Carrier FE & $\mathrm{x}$ & $\mathrm{x}$ & $\mathrm{x}$ & $\mathrm{x}$ & $\mathrm{x}$ & $\mathrm{x}$ & $\mathrm{x}$ & $\mathrm{x}$ & $\mathrm{x}$ \\
\hline \# Observations & $1,237,878$ & $1,237,878$ & $1,209,791$ & $1,237,878$ & $1,237,878$ & $1,209,791$ & $1,237,878$ & $1,237,878$ & $1,209,791$ \\
\hline $\mathrm{R}^{2}$ & 0.82 & 0.83 & 0.84 & 0.82 & 0.83 & 0.84 & 0.82 & 0.83 & 0.84 \\
\hline \# Market-carriers & 46,510 & 46,510 & 45,244 & 46,510 & 46,510 & 45,244 & 46,510 & 46,510 & 45,244 \\
\hline
\end{tabular}

Panel B: Market Level Regressions

\begin{tabular}{|c|c|c|c|c|c|c|c|c|c|}
\hline & \multicolumn{3}{|c|}{ AST Aggregation } & \multicolumn{3}{|c|}{ No Aggregation } & \multicolumn{3}{|c|}{ DGS Aggregation } \\
\hline & (1) & (2) & (3) & (7) & (8) & (9) & (4) & (5) & (6) \\
\hline$H H I \Delta$ & $\begin{array}{c}0.323^{* * *} \\
(0.045)\end{array}$ & $\begin{array}{c}0.342^{* * *} \\
(0.041)\end{array}$ & $\begin{array}{c}0.196^{* * *} \\
(0.036)\end{array}$ & $\begin{array}{c}0.347^{* * *} \\
(0.048)\end{array}$ & $\begin{array}{c}0.360^{* * *} \\
(0.044)\end{array}$ & $\begin{array}{c}0.200^{* * *} \\
(0.039)\end{array}$ & $\begin{array}{c}0.335^{* * *} \\
(0.046)\end{array}$ & $\begin{array}{c}0.357^{* * *} \\
(0.041)\end{array}$ & $\begin{array}{c}0.210^{* * *} \\
(0.037)\end{array}$ \\
\hline$H H I$ & $\begin{array}{c}0.365^{* * *} \\
(0.032)\end{array}$ & $\begin{array}{c}0.364^{* * *} \\
(0.032)\end{array}$ & $\begin{array}{c}0.255^{* * *} \\
(0.025)\end{array}$ & $\begin{array}{c}0.366^{* * *} \\
(0.031)\end{array}$ & $\begin{array}{c}0.363^{* * *} \\
(0.032)\end{array}$ & $\begin{array}{c}0.254^{* * *} \\
(0.024)\end{array}$ & $\begin{array}{c}0.367^{* * * *} \\
(0.032)\end{array}$ & $\begin{array}{c}0.367^{* * *} \\
(0.033)\end{array}$ & $\begin{array}{c}0.258^{* * *} \\
(0.025)\end{array}$ \\
\hline $\log ($ Distance $) \cdot$ Yr-Qtr FE & & $\mathrm{x}$ & $\mathrm{x}$ & & $\mathrm{x}$ & $\mathrm{x}$ & & $\mathrm{x}$ & $\mathrm{x}$ \\
\hline Full Set of Controls & & & $\mathrm{x}$ & & & $\mathrm{x}$ & & & $\mathrm{x}$ \\
\hline Year-Quarter FE & $\mathrm{x}$ & $\mathrm{x}$ & $\mathrm{x}$ & $\mathrm{x}$ & $\mathrm{x}$ & $\mathrm{x}$ & $\mathrm{x}$ & $\mathrm{x}$ & $\mathrm{x}$ \\
\hline Market-Carrier FE & $\mathrm{x}$ & $\mathrm{x}$ & $\mathrm{x}$ & $\mathrm{x}$ & $\mathrm{x}$ & $\mathrm{x}$ & $\mathrm{x}$ & $\mathrm{x}$ & $\mathrm{x}$ \\
\hline \# Observations & 262,534 & 262,534 & 255,173 & 262,534 & 262,534 & 255,173 & 262,534 & 262,534 & 255,173 \\
\hline $\mathrm{R}^{2}$ & 0.85 & 0.86 & 0.88 & 0.85 & 0.86 & 0.88 & 0.85 & 0.86 & 0.88 \\
\hline \# Markets & 7,190 & 7,190 & 6,911 & 7,190 & 7,190 & 6,911 & 7,190 & 7,190 & 6,911 \\
\hline
\end{tabular}

This table presents results using three different treatments for aggregating ownership and votes across funds within a fund family. Panel A reports market-carrier level regressions (equation (2)), and Panel B reports market level regressions (equation (3)). In each panel, the first three columns report results using AST's aggregation method; the middle three columns simply do not aggregate votes across funds in a fund family; and the last three columns reports results following an algorithm we developed to identify funds within a fund family, DGS Aggregation. The DGS aggregation strategy is as follows: For each year in our sample period we select the top 20 managers by assets under management. We then take the union of the top 20 managers, resulting in a set of 36 unique managers. From this set of managers select a reasonable keyword that is broad enough to identify all possible funds that may be in the same family, yet narrow enough to make the search manageable. Then we manually examine all fund managers that contain that keyword, and for each keyword, select the managers that are likely to be members of the same fund family. Table A.III in the Online Appendix shows the results. We present results for all three specifications, from the base to most saturated one. Robust standard errors, in parentheses, clustered by year-quarter and by market-carrier (Panel A) and market (Panel B). Robust standard errors, in parentheses, are clustered by year-quarter and by market-carrier (Panel A) and market (Panel B). Significance at the 1\%,5\% and $10 \%$ level is shown by ***, ** and *, respectively. 
Table VII. Chapter 11 Bankruptcy Reorganization

Bankruptcy Dates and Distribution for Interests (Equity) upon Reorganization

\begin{tabular}{|c|c|c|c|c|c|c|}
\hline \multirow{3}{*}{ Carrier } & \multirow{2}{*}{\multicolumn{2}{|c|}{$\begin{array}{c}\text { Bankruptcy } \\
\text { Dates }\end{array}$}} & \multicolumn{4}{|c|}{ Emerging From Bankruptcy } \\
\hline & & & \multirow[t]{2}{*}{ Document } & \multirow[t]{2}{*}{ Page(s) } & \multirow{2}{*}{$\begin{array}{c}\text { Date } \\
\text { Reported }\end{array}$} & \multirow{2}{*}{$\begin{array}{l}\text { Distribution } \\
\text { to Interests }\end{array}$} \\
\hline & Filed & Emerged & & & & \\
\hline United Airlines & $12 / 9 / 02$ & $2 / 2 / 06$ & SEC Form 8-K & $3-5$ & $1 / 20 / 06$ & 0 \\
\hline US Airways & $8 / 11 / 02$ & $3 / 31 / 03$ & Court Listener* & & & 0 \\
\hline US Airways & $9 / 12 / 04$ & $9 / 27 / 05$ & SEC Form $10-\mathrm{K}$ & 17 & $3 / 15 / 2006$ & 0 \\
\hline Delta & $9 / 14 / 05$ & $4 / 24 / 07$ & Disclosure Statement & & $12 / 19 / 06$ & 0 \\
\hline Northwest & $9 / 14 / 05$ & $5 / 18 / 07$ & SEC Form 8-K & 5 and 24 & $5 / 21 / 07$ & 0 \\
\hline Mesa & $1 / 5 / 10$ & $1 / 3 / 11$ & $\begin{array}{c}\text { 3rd Amended Joint } \\
\text { Plan of Reorganization }\end{array}$ & $\begin{array}{c}1,32, \\
\text { and } 36\end{array}$ & $1 / 19 / 11$ & 0 \\
\hline American Airlines & $11 / 29 / 11$ & $12 / 8 / 13$ & $\begin{array}{l}\text { AMR \& US Airways Merger: } \\
\text { Information for AMR Investors }\end{array}$ & 3 & $8 / 15 / 13$ & $\begin{array}{l}3.5 \% \text { of new } \\
\text { equity in merged carrier }\end{array}$ \\
\hline
\end{tabular}

This table reports the dates during which an airline operated under Chapter 11 Bankruptcy protection during our sample period (2000:Q1 to 2012:Q4), and the distribution (recovery) that pre-bankruptcy equity holders received when the carrier exited from bankruptcy protection (Column (5)). Figure A.1 in the Online Apppendix presents an excerpt of a disclosure statement for United Airlines. *Accessed May 2019, https://www.courtlistener. com/opinion/2014491/in-re-us-airways-group-inc/?q=US+Airways+2003\&type=o\&order_by=score+desc\&stat_ Precedential=on\&stat_Non-Precedential=on\&filed_after=2003-03-07\&filed_before=2003-03-07. 
Table VIII. Ownership and Control Through Bankruptcy

\begin{tabular}{|c|c|c|c|c|c|c|}
\hline & \multicolumn{6}{|c|}{ Different Ownership and Control Assumptions for Bankrupt Carriers } \\
\hline & \multicolumn{3}{|c|}{ Market-Carrier Level Regressions } & \multicolumn{3}{|c|}{ Market Level Regressions } \\
\hline & \multicolumn{3}{|c|}{ Ownership Through Bankruptcy? } & \multicolumn{3}{|c|}{ Ownership Through Bankruptcy? } \\
\hline & Pre-Bkt Forward & Post-Bkt Backward & No & Pre-Bkt Forward & Post-Bkt Backward & No \\
\hline & $H H I \Delta_{\text {CtrlBefore }}$ & $H H I \Delta_{C t r l A f t e r}$ & $H H I \Delta_{N o C t r l}$ & $H H I \Delta_{C t r l B e f o r e}$ & $H H I \Delta_{C t r l A f t e r}$ & $H H I \Delta_{N o C t r l}$ \\
\hline & $(1)$ & $(2)$ & $(3)$ & $(4)$ & $(5)$ & $(6)$ \\
\hline$H H I \Delta$ & $\begin{array}{c}0.147^{* * *} \\
(0.038)\end{array}$ & $\begin{array}{c}0.097^{* *} \\
(0.043)\end{array}$ & $\begin{array}{c}0.038 \\
(0.043)\end{array}$ & $\begin{array}{c}0.197^{* * *} \\
(0.036)\end{array}$ & $\begin{array}{c}0.159^{* * *} \\
(0.042)\end{array}$ & $\begin{array}{c}0.069 \\
(0.043)\end{array}$ \\
\hline$H H I$ & $\begin{array}{c}0.163^{* * *} \\
(0.021)\end{array}$ & $\begin{array}{c}0.150^{* * * *} \\
(0.022)\end{array}$ & $\begin{array}{c}0.133^{* * *} \\
(0.021)\end{array}$ & $\begin{array}{c}0.256^{* * * *} \\
(0.025)\end{array}$ & $\begin{array}{c}0.244^{* * *} \\
(0.026)\end{array}$ & $\begin{array}{c}0.218^{* * *} \\
(0.025)\end{array}$ \\
\hline $\log ($ Distance $) \cdot$ Year-Quarter FE & $\mathrm{x}$ & $\mathrm{x}$ & $\mathrm{x}$ & $\mathrm{x}$ & $\mathrm{x}$ & $\mathrm{x}$ \\
\hline Full Set of Controls & $\mathrm{x}$ & $\mathrm{x}$ & $\mathrm{x}$ & $\mathrm{x}$ & $\mathrm{x}$ & $\mathrm{x}$ \\
\hline Year-Quarter FE & $\mathrm{x}$ & $\mathrm{x}$ & $\mathrm{x}$ & $\mathrm{x}$ & $\mathrm{x}$ & $\mathrm{x}$ \\
\hline Market-Carrier FE & $\mathrm{x}$ & $\mathrm{x}$ & $\mathrm{x}$ & & & \\
\hline Carrier FE & & & & $\mathrm{x}$ & $\mathrm{x}$ & $\mathrm{x}$ \\
\hline \# Observations & $1,209,791$ & $1,209,791$ & $1,209,791$ & 255,173 & 255,173 & 255,173 \\
\hline $\mathrm{R}^{2}$ & 0.84 & 0.84 & 0.84 & 0.88 & 0.88 & 0.88 \\
\hline \# Market-Carriers & 45,244 & 45,244 & 45,244 & & & \\
\hline \# Markets & & & & 6,911 & 6,911 & 6,911 \\
\hline
\end{tabular}

This table presents results re-estimating equations (2) and (3) using alternative measures of $H H I \Delta$, with each one corresponding to a different assumption regarding who owns and controls a firm that operates under Chapter 11 Bankruptcy. Columns (1) and (4) correspond to AST's specification, which carry the pre-bankruptcy ownership

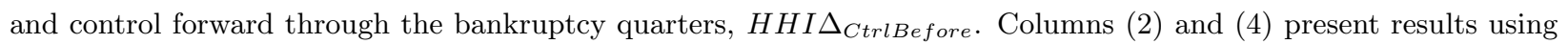
HHI $\Delta_{C t r l \text { fter }}$, constructed by carrying post-bankruptcy ownership and control backward through the bankruptcy quarters using the first post-bankruptcy reported shares. This sets cash flow and control rights of equity holders during the Chapter 11 time period equal to the value of ownership and control first observed upon the firm's emergence from bankruptcy. Columns (3) and (5) show results obtained using $H H I \Delta_{N o C t r l}$, constructed by setting ownership and control during the time the firm operates under bankruptcy court protection to zero. Columns (1)-(3) report marketcarrier regressions and Columns (4)-(6) report market-level regressions. Robust standard errors, in parentheses, are clustered by year-quarter and by market-carrier (Columns (1)-(30) and market (Columns (2)-(4)). Significance at the $1 \%, 5 \%$ and $10 \%$ level is shown by ${ }^{* * *}, * *$ and $*$, respectively. 
Table IX. Identification: The Effect of Voting Designations

\begin{tabular}{|c|c|c|c|c|c|c|}
\hline & \multicolumn{3}{|c|}{ Market-Carrier Level Regressions } & \multicolumn{3}{|c|}{ Market-Level regressions } \\
\hline & $H H I \Delta_{\text {Sole }+ \text { Shared }}$ & HHI $\Delta_{\text {Sole }}$ & $H H I \Delta_{\text {Owned }}$ & HHI $\Delta_{\text {Sole+Shared }}$ & $H H I \Delta_{\text {Sole }}$ & HHI $\Delta_{\text {Owned }}$ \\
\hline & (1) & $(2)$ & (3) & (4) & (5) & (6) \\
\hline$H H I \Delta$ & $\begin{array}{c}0.147^{* * *} \\
(0.038)\end{array}$ & $\begin{array}{c}0.152^{* * *} \\
(0.035)\end{array}$ & $\begin{array}{c}0.044 \\
(0.031)\end{array}$ & $\begin{array}{c}0.196^{* * *} \\
(0.036)\end{array}$ & $\begin{array}{c}0.197^{* * * *} \\
(0.034)\end{array}$ & $\begin{array}{c}0.104^{* * *} \\
(0.034)\end{array}$ \\
\hline$H H I$ & $\begin{array}{c}0.163^{* * *} \\
(0.021)\end{array}$ & $\begin{array}{c}0.168^{* * *} \\
(0.021)\end{array}$ & $\begin{array}{c}0.138^{* * *} \\
(0.021)\end{array}$ & $\begin{array}{c}0.255^{* * *} \\
(0.025)\end{array}$ & $\begin{array}{c}0.260^{* * *} \\
(0.024)\end{array}$ & $\begin{array}{c}0.235^{* * *} \\
(0.025)\end{array}$ \\
\hline Log(Distance) · Year-Quarter FE & $\mathrm{x}$ & $\mathrm{x}$ & $\mathrm{x}$ & $\mathrm{x}$ & $\mathrm{x}$ & $\mathrm{x}$ \\
\hline Full Set of Controls & $\mathrm{x}$ & $\mathrm{x}$ & $\mathrm{x}$ & $\mathrm{x}$ & $\mathrm{x}$ & $\mathrm{x}$ \\
\hline Year-Quarter FE & $\mathrm{x}$ & $\mathrm{x}$ & $\mathrm{x}$ & $\mathrm{x}$ & $\mathrm{x}$ & $\mathrm{x}$ \\
\hline Market-Carrier FE & $\mathrm{x}$ & $\mathrm{x}$ & $\mathrm{x}$ & & & \\
\hline Market FE & & & & $\mathrm{x}$ & $\mathrm{x}$ & $\mathrm{x}$ \\
\hline \# Observations & $1,209,791$ & $1,209,791$ & $1,209,791$ & 255,173 & 255,173 & 255,173 \\
\hline $\mathrm{R}^{2}$ & 0.84 & 0.84 & 0.84 & 0.88 & 0.88 & 0.88 \\
\hline \# Market-Carriers & 45,244 & 45,244 & 45,244 & & & \\
\hline \# Markets & & & & 6,911 & 6,911 & 6,911 \\
\hline
\end{tabular}

This table presents results obtained for three different measures of $H H I \Delta$, each one using a different designation of voting (control) rights. Shares owned by any institution can be designated as having "sole," "shared," or "no" voting authority. Columns (1)-(3) report market-carrier level regressions (equation (2)), and Columns (4)-(6) report market level regressions (equation (3)). We present results for the most saturated specification. For ease of comparison, Columns (1) and (4) present our replication of AST's results. Columns (2) and (5) present results using HHI $\Delta_{\text {Sole }}$ which sets control rights equal to shares with "sole" voting authority. Columns (3) and (6) present results using $H H I \Delta$ constructed by setting control rights equal to shares owned by the institution, HHI $\Delta_{\text {Owned }}$. Robust standard errors, in parentheses, are clustered by year-quarter and by market-carrier (Columns (1)-(3)) and market (Columns (4)-(6)). Significance at the $1 \%, 5 \%$ and $10 \%$ level is shown by $* * *, * *$ and $*$, respectively. 
Table X. The Effect of Using Regression Weights

\begin{tabular}{|c|c|c|c|c|}
\hline & \multicolumn{2}{|c|}{ Market-Carrier Level Regressions } & \multicolumn{2}{|c|}{ Market Level Regressions } \\
\hline & $\begin{array}{l}\text { Weights } \\
\text { (1) }\end{array}$ & $\begin{array}{l}\text { No Weights } \\
(2)\end{array}$ & $\begin{array}{l}\text { Weights } \\
(3)\end{array}$ & $\begin{array}{c}\text { No Weights } \\
(4)\end{array}$ \\
\hline$H H I \Delta$ & $\begin{array}{c}0.147^{* * *} \\
(0.038)\end{array}$ & $\begin{array}{l}0.045^{* *} \\
(0.022)\end{array}$ & $\begin{array}{c}0.196^{* * *} \\
(0.036)\end{array}$ & $\begin{array}{c}0.149^{* * *} \\
(0.026)\end{array}$ \\
\hline$H H I$ & $\begin{array}{c}0.163^{* * * *} \\
(0.021)\end{array}$ & $\begin{array}{c}0.193^{* * *} \\
(0.013)\end{array}$ & $\begin{array}{c}0.255^{* * *} \\
(0.025)\end{array}$ & $\begin{array}{c}0.221^{* * * *} \\
(0.019)\end{array}$ \\
\hline Log(Distance $) \cdot$ Yr-Qtr FE & $\mathrm{x}$ & $\mathrm{x}$ & $\mathrm{x}$ & $\mathrm{x}$ \\
\hline Full Set of Regressors & $\mathrm{x}$ & $\mathrm{x}$ & $\mathrm{x}$ & $\mathrm{x}$ \\
\hline Year-Quarter FE & $\mathrm{x}$ & $\mathrm{x}$ & $\mathrm{x}$ & $\mathrm{x}$ \\
\hline Market-Carrier FE & $\mathrm{x}$ & $\mathrm{x}$ & $\mathrm{x}$ & $\mathrm{x}$ \\
\hline Regression Weights & $\mathrm{x}$ & & $\mathrm{x}$ & \\
\hline \# Observations & $1,209,791$ & $1,209,791$ & 255,173 & 255,173 \\
\hline $\mathrm{R}^{2}$ & 0.84 & 0.61 & 0.88 & 0.84 \\
\hline \# Market-Carriers & 45,244 & 45,244 & & \\
\hline \# Markets & & & 6,911 & 6,911 \\
\hline
\end{tabular}

This table presents the results from estimating the AST specification with and without regression weights based on passenger counts. Columns (1)-(2) display results at the market-carrier level. Columns (3)-(4) display similar results at the market level. Robust standard errors, in parentheses, are clustered by year-quarter and by market-carrier (Columns (1)-(2)) and market (Columns (3)-(4)). Significance at the $1 \%, 5 \%$ and $10 \%$ level is shown by ***, ** and *, respectively. 
Table XI. The Effect of Market Size

\begin{tabular}{|c|c|c|c|c|c|c|c|c|}
\hline \multicolumn{9}{|c|}{ Panel A: Market-Carrier Level Regressions } \\
\hline \multirow{3}{*}{ Passenger Count Percentile: } & \multicolumn{8}{|c|}{ Dependent Variable: Log(Average Fare) } \\
\hline & \multicolumn{2}{|c|}{$\mathrm{p} 50$} & \multicolumn{2}{|c|}{ p75 } & \multicolumn{2}{|c|}{$\mathrm{p} 90$} & \multicolumn{2}{|c|}{ p95 } \\
\hline & $\underset{(1)}{>}$ & $\begin{array}{c}\leq \\
(2)\end{array}$ & $\begin{array}{c}> \\
(3)\end{array}$ & $\underset{(4)}{\leq}$ & $\begin{array}{l}> \\
(5)\end{array}$ & $\underset{(6)}{\leq}$ & $\underset{(7)}{>}$ & $\underset{(8)}{\leq}$ \\
\hline$H H I \Delta$ & $\begin{array}{c}0.099^{* * *} \\
(0.024)\end{array}$ & $\begin{array}{c}0.010 \\
(0.022)\end{array}$ & $\begin{array}{c}0.145^{* * *} \\
(0.030)\end{array}$ & $\begin{array}{l}0.035^{*} \\
(0.021)\end{array}$ & $\begin{array}{c}0.190^{* * *} \\
(0.038)\end{array}$ & $\begin{array}{c}0.044^{* *} \\
(0.021)\end{array}$ & $\begin{array}{c}0.197^{* * *} \\
(0.049)\end{array}$ & $\begin{array}{c}0.049^{* *} \\
(0.021)\end{array}$ \\
\hline$H H I$ & $\begin{array}{c}0.187^{* * *} \\
(0.016)\end{array}$ & $\begin{array}{c}0.205^{* * *} \\
(0.014)\end{array}$ & $\begin{array}{c}0.181^{* * *} \\
(0.020)\end{array}$ & $\begin{array}{c}0.204^{* * *} \\
(0.013)\end{array}$ & $\begin{array}{c}0.192^{* * *} \\
(0.026)\end{array}$ & $\begin{array}{c}0.198^{* * *} \\
(0.013)\end{array}$ & $\begin{array}{c}0.164^{* * *} \\
(0.033)\end{array}$ & $\begin{array}{c}0.198^{* * *} \\
(0.013)\end{array}$ \\
\hline Log(Distance) $x$ Year-Qtr FEs & $\mathrm{x}$ & $\mathrm{x}$ & $\mathrm{x}$ & $\mathrm{x}$ & $\mathrm{x}$ & $\mathrm{x}$ & $\mathrm{x}$ & $\mathrm{x}$ \\
\hline Full Set of Controls & $\mathrm{x}$ & $\mathrm{x}$ & $\mathrm{x}$ & $\mathrm{x}$ & $\mathrm{x}$ & $\mathrm{x}$ & $\mathrm{x}$ & $\mathrm{x}$ \\
\hline Year-Qtr FEs & $\mathrm{x}$ & $\mathrm{x}$ & $\mathrm{x}$ & $\mathrm{x}$ & $\mathrm{x}$ & $\mathrm{x}$ & $\mathrm{x}$ & $\mathrm{x}$ \\
\hline Market-Carrier FEs & $\mathrm{x}$ & $\mathrm{x}$ & $\mathrm{x}$ & $\mathrm{x}$ & $\mathrm{x}$ & $\mathrm{x}$ & $\mathrm{x}$ & $\mathrm{x}$ \\
\hline \# Observations & 606,852 & 602,425 & 303,598 & 905,825 & 121,539 & $1,088,095$ & 60,949 & $1,148,752$ \\
\hline $\mathrm{R}^{2}$ & 0.74 & 0.51 & 0.78 & 0.54 & 0.83 & 0.57 & 0.85 & 0.59 \\
\hline \# Market-Carriers & 18,412 & 29,569 & 8,737 & 38,294 & 3,464 & 42,578 & 1,631 & 43,987 \\
\hline
\end{tabular}

Panel B: Market Level Regressions

\begin{tabular}{|c|c|c|c|c|c|c|c|c|}
\hline \multirow{3}{*}{ Passenger Count Percentile: } & \multicolumn{8}{|c|}{ Dependent Variable: $\log$ (Average Fare) } \\
\hline & \multicolumn{2}{|c|}{ p50 } & \multicolumn{2}{|c|}{$\mathrm{p} 75$} & \multicolumn{2}{|c|}{$\mathrm{p} 90$} & \multicolumn{2}{|c|}{ p95 } \\
\hline & $\underset{(1)}{>}$ & $\begin{array}{c}\leq \\
(2)\end{array}$ & $\begin{array}{c}> \\
(3)\end{array}$ & $\underset{(4)}{\leq}$ & $\begin{array}{l}> \\
(5)\end{array}$ & $\begin{array}{l}\leq \\
(6)\end{array}$ & $\begin{array}{c}> \\
(7)\end{array}$ & $\underset{(8)}{\leq}$ \\
\hline$H H I \Delta$ & $\begin{array}{c}0.188^{* * *} \\
(0.031)\end{array}$ & $\begin{array}{c}0.168^{* * *} \\
(0.026)\end{array}$ & $\begin{array}{c}0.169^{* * *} \\
(0.041)\end{array}$ & $\begin{array}{c}0.186^{* * *} \\
(0.027)\end{array}$ & $\begin{array}{c}0.265^{* * *} \\
(0.050)\end{array}$ & $\begin{array}{c}0.160^{* * *} \\
(0.0273)\end{array}$ & $\begin{array}{c}0.316^{* * *} \\
(0.061)\end{array}$ & $\begin{array}{c}0.153^{* * *} \\
(0.027)\end{array}$ \\
\hline$H H I$ & $\begin{array}{c}0.273^{* * *} \\
(0.023)\end{array}$ & $\begin{array}{c}0.193^{* * *} \\
(0.019)\end{array}$ & $\begin{array}{c}0.250^{* * *} \\
(0.030)\end{array}$ & $\begin{array}{c}0.228^{* * *} \\
(0.019)\end{array}$ & $\begin{array}{c}0.317^{* * *} \\
(0.046)\end{array}$ & $\begin{array}{c}0.218^{* * *} \\
(0.019)\end{array}$ & $\begin{array}{c}0.272^{* * *} \\
(0.048)\end{array}$ & $\begin{array}{c}0.220^{* * *} \\
(0.019)\end{array}$ \\
\hline $\log ($ Distance $) \cdot$ Year-Qtr FEs & $\mathrm{x}$ & $\mathrm{x}$ & $\mathrm{x}$ & $\mathrm{x}$ & $\mathrm{x}$ & $\mathrm{x}$ & $\mathrm{x}$ & $\mathrm{x}$ \\
\hline Full Set of Controls & $\mathrm{x}$ & $\mathrm{x}$ & $\mathrm{x}$ & $\mathrm{x}$ & $\mathrm{x}$ & $\mathrm{x}$ & $\mathrm{x}$ & $\mathrm{x}$ \\
\hline Year-Qtr FEs & $\mathrm{x}$ & $\mathrm{x}$ & $\mathrm{x}$ & $\mathrm{x}$ & $\mathrm{x}$ & $\mathrm{x}$ & $\mathrm{x}$ & $\mathrm{x}$ \\
\hline Market FEs & $\mathrm{x}$ & $\mathrm{x}$ & $\mathrm{x}$ & $\mathrm{x}$ & $\mathrm{x}$ & $\mathrm{x}$ & $\mathrm{x}$ & $\mathrm{x}$ \\
\hline \# Observations & 128,294 & 126,800 & 64,585 & 190,562 & 25,830 & 229,337 & 12,893 & 242,277 \\
\hline $\mathrm{R}^{2}$ & 0.85 & 0.80 & 0.86 & 0.82 & 0.86 & 0.83 & 0.90 & 0.83 \\
\hline \# Markets & 2,657 & 4,650 & 1,251 & 5,826 & 497 & 6,485 & 246 & 6,702 \\
\hline
\end{tabular}

This table presents results from estimating the AST specification by partitioning the sample into high and low passenger counts. Panel A display results at the market-carrier level and Panel B displays results at the market level. The set of controls includes the number of nonstop carriers, a Southwest indicator, an other LCC indicator, the share of passengers traveling connect at the market level, the share of passengers traveling connect at the market-carrier level, $\log$ (population), and $\log$ (income per capita). Robust standard errors, in parentheses, are clustered by yearquarter and by market-carrier (Paenl A) and market (Panel B). Significance at the 1\%, 5\% and 10\% level is shown by $* * *, * *$ and $*$, respectively. 
Figure 1. Identification: True Market Shares and Placebo Ownership

\section{Panel A: Market-Carrier Level Regressions}

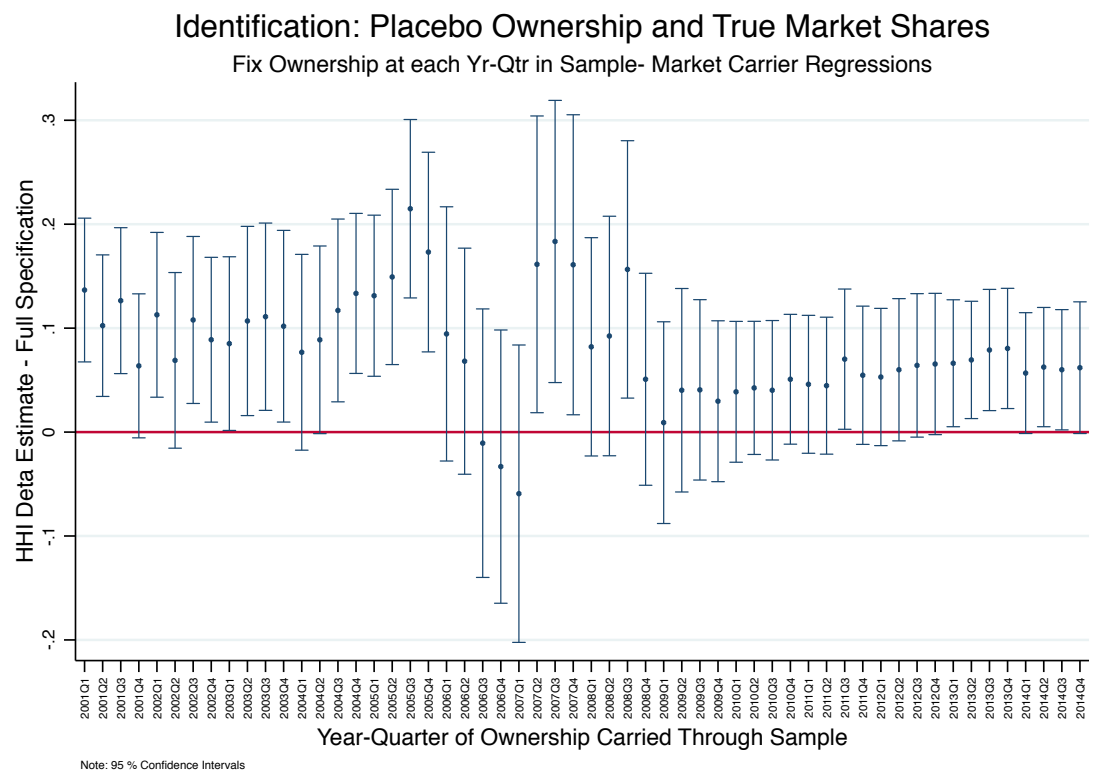

Panel B: Market Level Regressions

Identification: Placebo Ownership and True Market Shares

Fix Ownership at each Yr-Qtr in Sample - Market Level Regressions

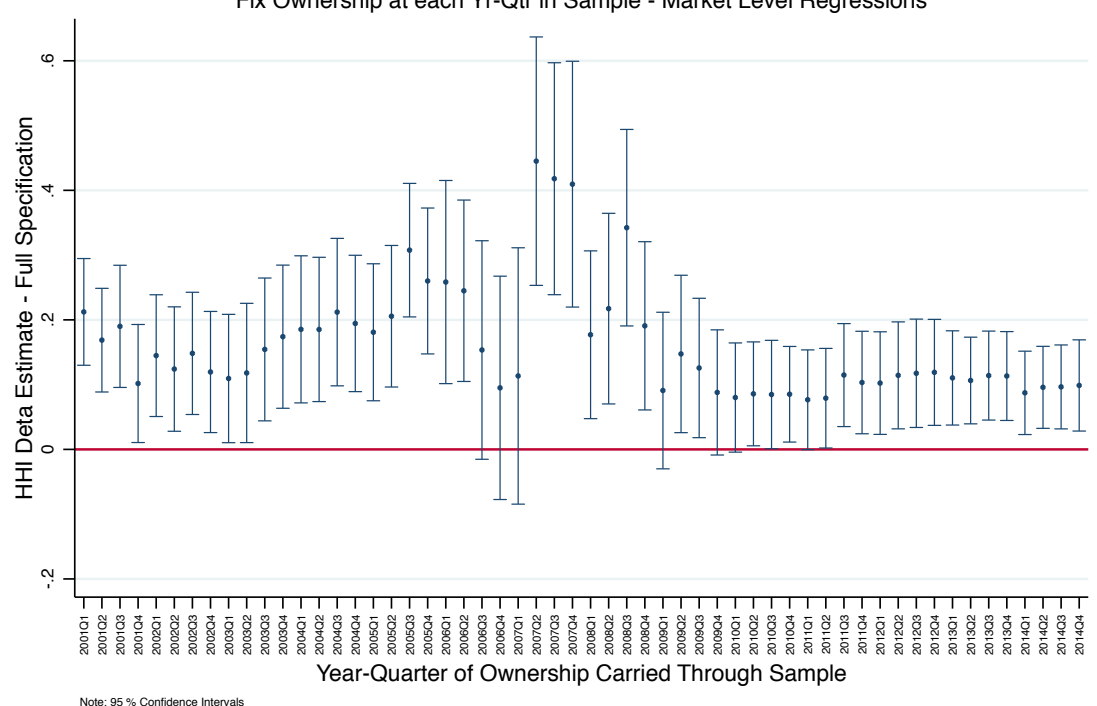

Panel A plots the coefficient estimates of $H H I \Delta_{\text {TrueMS }}^{\text {Placebo }}{ }^{\text {own }}$ for each of the 56 market-carrier level regressions:

$$
\log \left(p_{r j t}\right)=\alpha \cdot\left(H H I \Delta_{\text {TrueMS }}^{\text {PlaceboOwn }}\right)_{r t}+\eta \cdot H H I_{r t}+\theta \cdot X_{r j t}+\alpha_{t}+\nu_{r j}+\varepsilon_{r j t} .
$$

Panel B plots coefficients estimates of $H H I \Delta_{\text {TrueMS }}^{\text {Placebo }}$ Own for each of the 56 market level regressions:

$$
\log \left(p_{r t}\right)=\alpha \cdot\left(H H I \Delta_{\text {True } M S}^{\text {PlaceboOn }}\right)_{r t}+\eta \cdot H H I_{r t}+\theta \cdot X_{r t}+\alpha_{t}+\nu_{r}+\varepsilon_{r t} .
$$

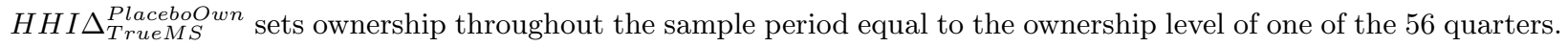
Point estimates are shown as dots along with $95 \%$ confidence intervals for each of the 56 coefficient estimates. 
Figure 2. Measuring Control Rights: Different Voting Designations

\section{Inconsistent Across Institutions, Times, and Within Institutions Across Time}
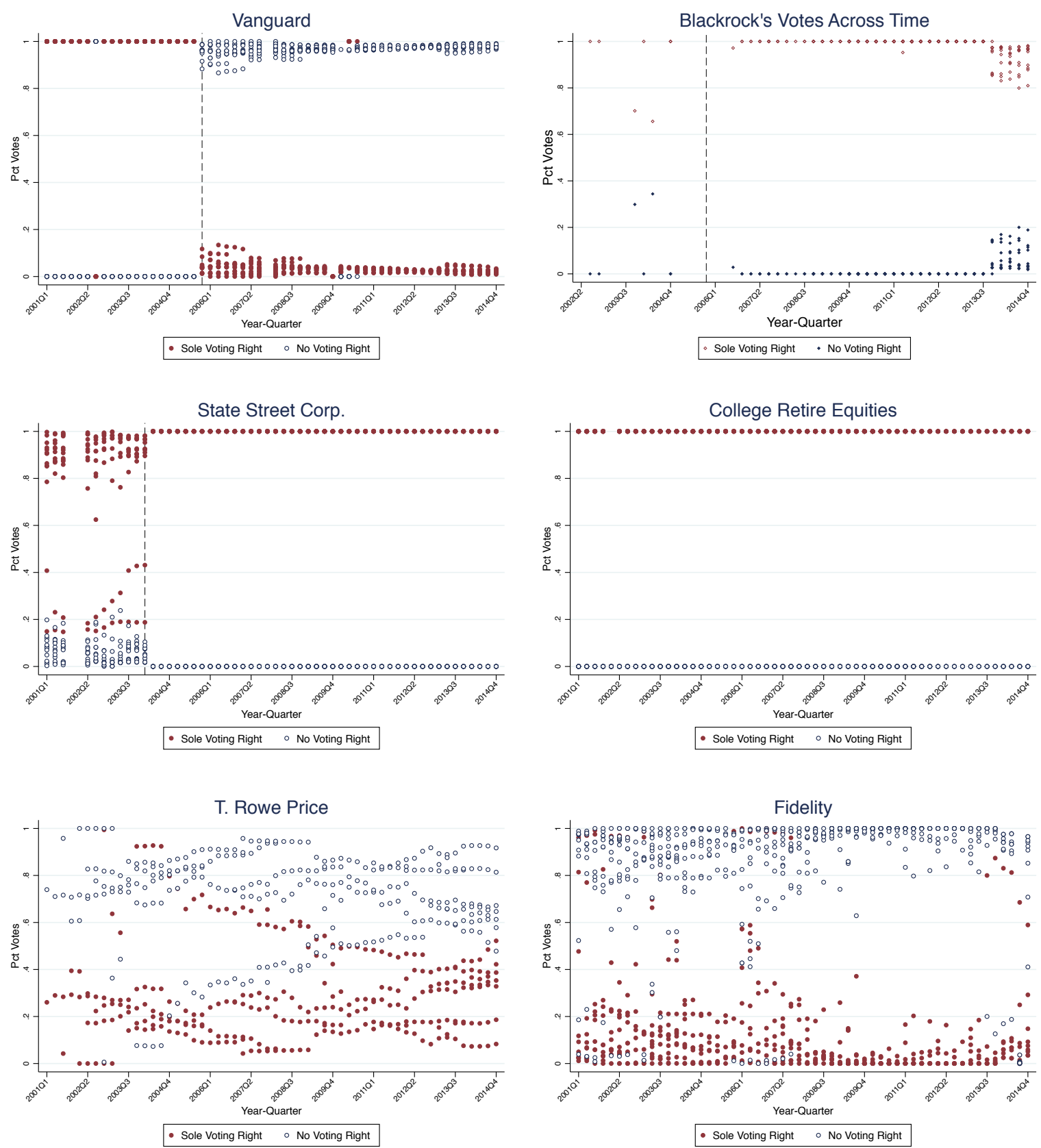

For a sub-sample of institutions in our data set, we plot the percent of shares designated with "sole", as well as those with "no" voting right, as a fraction of all shares owned, for each year-quarter observation in our sample. The inconsistencies reported across funds and within a fund across time, is consistent with SEC officials reporting that the "Special Instruction 12.b.viii to Form 13F" guidelines are vague, and reporting depends on how each institution interprets the guidelines. For instance, Vanguard switched to designating all shares owned as having no voting right, in the third quarter of 2005; while State Street reported some shares as having sole, others as no, voting authority prior to the first quarter of 2004, after this designating all shares as having sole voting authority (the reverse move of Vanguard's). 


\title{
Online Appendices (Not for Publication)
}

\section{Common Ownership Does Not Have Anti-Competitive Effects in the Airline Industry}

\author{
Patrick Dennis, Kristopher Gerardi \& Carola Schenone
}

June 28, 2019

\begin{abstract}
These appendices contain additional details on data set construction and further evidence supporting our findings. Appendix I contains a detailed explanation of the construction of $H H H \Delta$ and some basic intuition of how this variable captures the additional concentration due to common ownership. Appendix II contains the results from the first stage instrumental variable regressions in Table V. Appendix III contains details on our algorithm of aggregating cash flow and voting rights to the fund-family level. Appendix IV contains a sample exhibit from United Airline's bankruptcy disclosure and a plot of the distribution of $\mathrm{HHH} \Delta$ using various assumptions regarding ownership during bankruptcy. Last, Appendix V contains some additional details regarding voting rights.
\end{abstract}




\section{Appendix I. Measure of Market Concentration}

First, we briefly review the definition of the additional market concentration due to common ownership in Bresnahan and Salop (1986) and O'Brien and Salop (2000), and then we give some intuition regarding how this measure works. Firms are denoted by $j$ and $k$, and there are $m$ owners and $n$ firms in the product market. Let $\gamma_{j}$ be a $m \times 1$ vector of control rights and $\beta_{j}$ be a $m \times 1$ vector of cash-flow rights for firm $j$. Each element in $\gamma_{j}$ and $\beta_{j}$ corresponds to one of the $m$ owners. Firms compete in a Cournot setting with the manager of firm $j$ choosing an output quantity $x_{j}$ to maximize a weighted average of the profits of all $m$ owners of the firm: $\max _{x_{j}} \gamma_{j}^{\prime} \pi$, where $\pi$ is an $m \times 1$ vector of profits accruing to each of the $m$ owners. The weights in the objective function are control rights, not cash-flow rights, since it is the owner's control rights that matter to the manager. If an owner has cash flow rights but no control rights, then the owner has no recourse against the manager if the manager does not act in the owner's interest. The profit to each owner, represented by the elements of $\pi$, is the sum of an owner's ownership share in each firm multiplied by that firm's profits. Setting the first-order condition equal to 0 yields the modified Herfindahl-Hirschman index $(M H H I)$, which is a measure of market concentration accounting for common ownership.

The market shares for each of the $n$ firms are given by the $n \times 1$ vector $S$, hence the ordinary Herfindahl-Hirschman index $(H H I)$ without considering the anti-competitive effects of common ownership is $S^{\prime} S$. Define the $n \times n$ matrix $C$ as the "concentration matrix" which provides a set of weights defining the additional concentration due to common ownership:

$$
C=\left[\begin{array}{rrrr}
0 & \frac{\gamma_{1}^{\prime} \beta_{2}}{\gamma_{1}^{\prime} \beta_{1}} & \ldots & \frac{\gamma_{1}^{\prime} \beta_{n}}{\gamma_{1}^{\prime} \beta_{1}} \\
\frac{\gamma_{2}^{\prime} \beta_{1}}{\gamma_{2}^{\prime} \beta_{2}} & 0 & \ldots & \frac{\gamma_{2}^{\prime} \beta_{n}}{\gamma_{2}^{\prime} \beta_{2}} \\
\vdots & \vdots & \ddots & \vdots \\
\frac{\gamma_{n}^{\prime} \beta_{1}}{\gamma_{n}^{\prime} \beta_{n}} & \frac{\gamma_{n}^{\prime} \beta_{2}}{\gamma_{n}^{\prime} \beta_{n}} & \ldots & 0
\end{array}\right]
$$

The $M H H I$ that results from each manager in the market maximizing the weighted-average profits of all owners in their firm is

$$
M H H I=\underbrace{S^{\prime} S}_{H H I}+\underbrace{S^{\prime} C S}_{H H I \Delta}
$$

The MHHI consists of the unadjusted HHI plus the additional market concentration due to 
common ownership, HHI .

To understand how this measure captures additional concentration due to common ownership, consider two firms, say 5 and 7. The additional market concentration due to common ownership will be the product of the market shares of the two firms, $s_{5}$ and $s_{7}$, weighted by the term $\frac{\gamma_{5}^{\prime} \beta_{7}}{\gamma_{5}^{\prime} \beta_{5}}+\frac{\gamma_{7}^{\prime} \beta_{5}}{\gamma_{7}^{\prime} \beta_{7}}$. The numerator in the first term captures the across-firm concentration: if an owner has control rights to firm 5 and cash-flow rights to firm 7, then they will use their control rights to influence firm 5 to compete less with firm 7. The denominator in the first term captures the within-firm concentration: if an owner has both control rights and cash flow rights to firm 5 , then to maximize the owner's profit, the manager of firm 5 competes more with firm 7, maximizing profits accruing to firm 5 at the expense of the joint profit accruing to both firms 5 and 7 . The interpretation of the second term is analogous to that of the first term. Hence, the weight applied to $s_{5} s_{7}$ when computing the HHID is the ratio of the numerators, which capture across-firm concentration to the denominators, which capture within-firm concentration.

Some examples help illustrate this. ${ }^{1}$ Consider a simple market with only two firms, 1 and 2 , and two owners, A and B.

- Example 1: If A owns all of firm 1 and B owns all of firm 2, then $\gamma_{1}=\beta_{1}=\left[\begin{array}{ll}1 & 0\end{array}\right]^{\prime}$ and $\gamma_{2}=\beta_{2}=\left[\begin{array}{ll}0 & 1\end{array}\right]^{\prime}$. Since there is no cross-ownership, both the matrix $C$ and the $H H I \Delta$ are zero.

- Example 2: As above, owner A still owns all of firm 1, but they also have a silent financial interest in firm 2. Specifically they receive a fraction $\alpha$ of the cash flows from firm 2 but they have no control rights. Now $\gamma_{1}=\beta_{1}=\left[\begin{array}{ll}1 & 0\end{array}\right]^{\prime}$ and $\gamma_{2}=\left[\begin{array}{ll}0 & 1\end{array}\right]^{\prime}$, however $\beta_{2}=$ $\left[\begin{array}{ll}\alpha & 1-\alpha\end{array}\right]^{\prime}$. This gives concentration weights of

$$
C=\left[\begin{array}{rr}
0 & \frac{\gamma_{1}^{\prime} \beta_{2}}{\gamma_{1}^{\prime} \beta_{1}} \\
\frac{\gamma_{2}^{\prime} \beta_{1}}{\gamma_{2}^{\prime} \beta_{2}} & 0
\end{array}\right]=\left[\begin{array}{ll}
0 & \alpha \\
0 & 0
\end{array}\right]
$$

and an $H H I \Delta$ of $\alpha s_{5} s_{7}$. While owner A does not have any control rights over firm 1, they now own $\alpha$ of firm 2 and also control firm 1, hence they can influence firm 1 to not compete

\footnotetext{
${ }^{1}$ These come from the appendix O'Brien and Salop (2000) translated into our matrix notation.
} 
as aggressively with firm 2. This benefits owner A via increased profits from firm 2 .

- Example 3: In the example above, if owner A held a fraction $\alpha$ of both ownership and control rights in firm 2, then $\gamma_{1}=\beta_{1}=\left[\begin{array}{ll}1 & 0\end{array}\right]^{\prime}$ and $\gamma_{2}=\beta_{2}=\left[\begin{array}{cc}\alpha & 1-\alpha\end{array}\right]^{\prime}$. This gives concentration weights of

$$
C=\left[\begin{array}{rr}
0 & \frac{\gamma_{1}^{\prime} \beta_{2}}{\gamma_{1}^{\prime} \beta_{1}} \\
\frac{\gamma_{2}^{\prime} \beta_{1}}{\gamma_{2}^{\prime} \beta_{2}} & 0
\end{array}\right]=\left[\begin{array}{rr}
0 & \alpha \\
\frac{\alpha}{\alpha^{2}+(1-\alpha)^{2}} & 0
\end{array}\right]
$$

and an $H H I \Delta$ of $\left(\frac{\gamma_{1}^{\prime} \beta_{2}}{\gamma_{1}^{\prime} \beta_{1}}+\frac{\gamma_{2}^{\prime} \beta_{1}}{\gamma_{2}^{\prime} \beta_{2}}\right) s_{1} s_{2}=2 \alpha\left(\frac{\alpha^{2}-\alpha+1}{2\left(\alpha^{2}-\alpha\right)+1}\right) s_{1} s_{2}$. The concentration is greater here than in the prior example since owner A has an ownership stake in and control rights to both firms. Now owner A can influence the managers of both firms, as opposed to only firm 1 , to compete less aggressively. 


\section{Appendix II. Endogeneity: First Stage Regression Results}

Table A.I. Endogeneity: IV First Stage Regressions

\begin{tabular}{lcc}
\hline & $\begin{array}{c}\text { For Specification }(3) \\
\text { in Table V }\end{array}$ & $\begin{array}{c}\text { Specification }(4) \\
\text { in Table V }\end{array}$ \\
\hline & $(1)$ & $(2)$ \\
\hline irutherf & $0.248^{* * *}$ & $H H I \Delta$ \\
HHI $\Delta_{I V}$ & $(0.020)$ & $0.051^{* * *}$ \\
& $-0.144^{* * *}$ & $0.009)$ \\
Number of & $(0.018)$ & $(0.024)$ \\
Nonstop Carriers & $-0.030^{* * *}$ & $0.005^{* * *}$ \\
Southwest Indicator & $(0.002)$ & $(0.001)$ \\
& $-0.056^{* * *}$ & $0.028^{* * *}$ \\
Other LCC Indicator & $(0.007)$ & $(0.005)$ \\
& $-0.065^{* * *}$ & $-0.012^{* * *}$ \\
Share of Passengers & $(0.008)$ & $(0.003)$ \\
Traveling Connect, Mkt-Level & $-0.383^{* * *}$ & $0.165^{* * *}$ \\
Share of Passengers & $(0.011)$ & $(0.007)$ \\
Traveling Connect & $0.042^{* * *}$ & $-0.029^{* * *}$ \\
Log(Population) & $(0.005)$ & $(0.003)$ \\
& $-0.178^{* *}$ & $0.209^{* * *}$ \\
Log(Income Per Capita) & $(0.086)$ & $(0.054)$ \\
& -0.049 & $0.181^{* * *}$ \\
\hline Log(Distance) x Year-Quarter FE & $(0.050)$ & $(0.042)$ \\
Year-Quarter FE & $\mathrm{x}$ & $\mathrm{x}$ \\
Market-Carrier FE & $\mathrm{x}$ & $\mathrm{x}$ \\
Origin x Time Trend & $\mathrm{x}$ & $\mathrm{x}$ \\
Destination x Time Trend & $\mathrm{x}$ & $\mathrm{x}$ \\
\hline Observations & 338,358 & 36,766 \\
Number of market-carrier pairs & 36,766 & \\
\hline & & $\mathrm{x}$ \\
\hline
\end{tabular}

This table presents results for the first stage estimation of the instrumental variable specification described in Section III, and Table V. We regress $H H I$ (column 1) and $H H I \Delta$ (column 2) on the instruments for $H H I$ and $H H I \Delta$, irutherf $f_{j r t}$ and $H H I \Delta_{I V}$ respectively, and the full set of exogenous covariates. Specifically, the instrument for $H H I$ is defined as first defined by Borenstein (1989),

$$
\text { irutherf } f_{j r t}={\widehat{s_{j r t}}}^{2}+\frac{H H I_{r t}-s_{j r t}^{2}}{\left(1-s_{j r t}\right)^{2}} \cdot\left(1-\widehat{s_{j r t}}\right)^{2} .
$$

We further instrument for HHI $\Delta$ using,

$$
H H I \Delta_{I V}=\sum_{j} \sum_{k \neq j} \frac{\sum_{i} \gamma_{i j} \beta_{i k}}{\sum_{i} \gamma_{i j} \beta_{i j}} \widehat{s_{j r t}} \cdot \widehat{s_{k r t}},
$$

where $\widehat{s_{j r t}}$ is the fitted value from the regression of market shares on genpash $h_{j r t}$,

$$
s_{j r t}=\alpha_{I V}+\beta_{I V} \cdot g e n p s h_{j r t}+\delta_{I V} \cdot X_{j r t}+\eta_{j r t},
$$

where genpash $h_{j t}$ is the instrument Borenstein (1989) developed by airline market shares. 


\section{Appendix III. Fund-Family Level Aggregation Algorithm}

The data in Thomson-Reuters (TR) database is not aggregated at the fund family level. Since manager names are stored in a 30 character field and are not necessarily consistently entered in the exact same format, a character-matching algorithm may lead to errors. For example, take American Express. Grouping all managers containing the keyword "AMERICAN" into the same family will lead to errors by grouping too many managers together (e.g. "AMERICAN FLETCHER BK\&TR" will be put into the same family as "AMERICAN EXPRESS COMPANY"). On the other hand, grouping all managers containing the keyword "AMERICAN EXPRESS" into the same family will lead to errors by grouping too few managers together (e.g. "AMERICAN EXP CO" and "AMERICAN EXPRESS COMPANY" would not be in the same family).

Our approach is to manually examine the manager names and then group managers together that could be in the same family - i.e. behave as a single entity that collectively shares cash flow and voting rights. Within our sample period, there are 7,710 unique character strings that identify different managers. To make the task manageable, we compute assets under management (AUM) for each manager as of December 31 for each year from 2000 to 2014. As shown in Table A.II, the top 20 funds comprise a good portion of AUM each year, from a minimum of $40.5 \%$ in 2014 to a maximum of $43.8 \%$ in 2003 . The last column shows the AUM of the largest fund not contained in the top 20, which, at most, is $1 \%$ of the total assets managed by all funds.

Next, we form the union of the sets of the top 20 managers for all years, yielding a final set of 36 unique managers. For each of these 36 managers, we select a reasonable keyword that is broad enough to identify all possible funds that may be in the same family, yet narrow enough to make the search manageable. Then we manually examine all fund managers that contain that keyword, and for each keyword, select the managers that are likely to be members of the same fund family. Table A.III shows the results. For example, a search for "BLACKROCK" yielded seven distinct managers in the TR database (TR manager numbers 9385, 11386, 12588, 39539, $56790,81575,91430)$ which we aggregated together and treated as a single institutional manager (family number 7 in Table A.III). As the list in Table A.III shows, we tended to be generous when doing the aggregation which should bias the resulting measure of common ownership upward. For example, we grouped "NORTHERN TRUST VALUE INVESTORS" and "NORTHERN TRUST 
COMPANY OF CT" together into fund family 29, even though in practice they may not aggregate their votes together and vote as a single entity. 
Table A.II. Fraction of Assets Under Management for the Top 20 Managers

\begin{tabular}{ccc}
\hline Year & Top 20 funds (\%) & 21st fund (\%) \\
\hline 2000 & 43.6 & 0.98 \\
2001 & 43.7 & 0.92 \\
2002 & 43.4 & 0.91 \\
2003 & 43.8 & 0.92 \\
2004 & 43.2 & 0.91 \\
2005 & 42.6 & 1.00 \\
2006 & 42.7 & 0.86 \\
2007 & 42.2 & 0.94 \\
2008 & 43.3 & 0.77 \\
2009 & 42.2 & 0.77 \\
2010 & 41.9 & 0.77 \\
2011 & 41.8 & 0.73 \\
2012 & 42.1 & 0.70 \\
2013 & 42.4 & 0.70 \\
2014 & 40.5 & 0.63 \\
\hline
\end{tabular}

This table shows the Assets Under Management (AUM) of top 20 fund managers in the ThompsonReuters $13 \mathrm{~F}$ database for 2000 to 2014 . The second column is the fraction of the AUM for the combined top 20 funds as a fraction of the total AUM for all funds as of December 31 each year. The last column is the fraction of AUM of the largest fund not in the top 20. 
Table A.III. Aggregation at the Fund-Family Level

\begin{tabular}{|c|c|c|c|}
\hline Manager Name & Manager Number & Keyword & Family Number \\
\hline AIM FUNDS MANAGEMENT, INC. & 138 & AIM & 1 \\
\hline AIM TRIMARK INVESTMENTS & 138 & AIM & 1 \\
\hline AIM MANAGEMENT GROUP, INC. & 140 & AIM & 1 \\
\hline AIM MANAGEMENT GROUP,INC. & 140 & AIM & 1 \\
\hline AMERICAN EXPRESS COMPANY & 1790 & AMERICAN & 2 \\
\hline AMERICAN EXP FINANCIAL ADVR & 45639 & AMERICAN & 2 \\
\hline AMERICAN EXPRESS FINANCIAL ADV & 45639 & AMERICAN & 2 \\
\hline AMERICAN EXPRESS FINL ADVR & 45639 & AMERICAN & 2 \\
\hline AMERICAN EXP ASSET MGMT LTD.(H & 45645 & AMERICAN & 2 \\
\hline AMERICAN EXPRESS ASSET MANAGEM & 45645 & AMERICAN & 2 \\
\hline AMERICAN EXPRESS ASSET MGMT LT & 45645 & AMERICAN & 2 \\
\hline AMERICAN EXP ASSET MGMT INTL J & 45648 & AMERICAN & 2 \\
\hline AMERICAN EXPRESS ASSET MGMT IN & 45648 & AMERICAN & 2 \\
\hline AMERICAN EXP ASSET MGMT INTL(J & 45655 & AMERICAN & 2 \\
\hline AMERICAN EXPRESS ASSET MGMT IN & 45655 & AMERICAN & 2 \\
\hline AMVESCAP PLC LONDON & 10586 & AMVESCAP & 3 \\
\hline AMVESCAP PLC & 47450 & AMVESCAP & 3 \\
\hline AXA FINANCIAL, INC. & 25610 & AXA & 4 \\
\hline BANK OF AMERICA CORPORATION & 62890 & AMERICA & 5 \\
\hline BARCLAYS BANK PLC & 7900 & BARCLAYS & 6 \\
\hline BARCLAYS BK PLC-NY BRANCH & 7905 & BARCLAYS & 6 \\
\hline BARCLAYS BK PLC-NY BRNCH & 7905 & BARCLAYS & 6 \\
\hline BARCLAYS WEALTH TRUSTEES(U.S.) & 13976 & BARCLAYS & 6 \\
\hline BLACKROCK FINL MGMT, INC. & 9385 & BLACKROCK & 7 \\
\hline BLACKROCK INC & 9385 & BLACKROCK & 7 \\
\hline BLACKROCK, INC. & 9385 & BLACKROCK & 7 \\
\hline BLACKROCK ADVISORS, LLC & 11386 & BLACKROCK & 7 \\
\hline BLACKROCK ASSET MGMT IRELAND L & 12588 & BLACKROCK & 7 \\
\hline BLACKROCK FINL MGMT, INC. (ML) & 39539 & BLACKROCK & 7 \\
\hline BLACKROCK INVESTMENT MGMT, LLC & 39539 & BLACKROCK & 7 \\
\hline BLACKROCK JAPAN CO., LTD. & 56790 & BLACKROCK & 7 \\
\hline BLACKROCK FINL MGMT (SSR\&M) & 81575 & BLACKROCK & 7 \\
\hline BLACKROCK INVT MGMT (UK) LTD. & 91430 & BLACKROCK & 7 \\
\hline CAPITAL RESEARCH \& MANAGEMENT & 12740 & CAPITAL RESEARCH & 8 \\
\hline CAPITAL RESEARCH \& MGMT CO & 12740 & CAPITAL RESEARCH & 8 \\
\hline CAPITAL RESEARCH \& MGMT CO. & 12740 & CAPITAL RESEARCH & 8 \\
\hline CAPITAL RESEARCH \& MGMT CO_NLE & 12740 & CAPITAL RESEARCH & 8 \\
\hline CAPITAL RESEARCH GBL INVESTORS & 11835 & CAPITAL & 9 \\
\hline CAPITAL WORLD INVESTORS & 11836 & CAPITAL & 9 \\
\hline CITIGROUP INC & 84900 & CITIGROUP & 10 \\
\hline CITIGROUP INVESTMENTS INC. & 84900 & CITIGROUP & 10 \\
\hline COLLEGE RETIRE EQUITIES & 18265 & COLLEGE & 11 \\
\hline COLLEGE RETIREMENT EQUITIES FD & 84205 & COLLEGE & 11 \\
\hline COLUMBIA MGMT ADVISERS INC.(NE & 6124 & COLUMBIA & 12 \\
\hline COLUMBIA MGMT ADVISERS INC.(CO & 18460 & COLUMBIA & 12 \\
\hline COLUMBIA MANAGEMENT COMPANY & 18980 & COLUMBIA & 12 \\
\hline COLUMBIA MGMT ADVISERS INC.(OR & 18980 & COLUMBIA & 12 \\
\hline COLUMBIA MGMT ADVISORS INC.(CR & 21570 & COLUMBIA & 12 \\
\hline COLUMBIA MGMT INV ADVISERS LLC & 45639 & COLUMBIA & 12 \\
\hline COLUMBIA MGMT ADVISERS INC.(ST & 81770 & COLUMBIA & 12 \\
\hline DEUTSCHE BK AKTIENGESELLSCHAFT & 7800 & DEUTSCHE & 13 \\
\hline DEUTSCHE ASSET MANAGEMENT & 22912 & DEUTSCHE & 13 \\
\hline DEUTSCHE ASSET MGMT (US) & 22912 & DEUTSCHE & 13 \\
\hline
\end{tabular}


Table A.III. (continued): Aggregation at the Fund-Family Level

\begin{tabular}{|c|c|c|c|}
\hline Manager Name & Manager Number & Keyword & Family Number \\
\hline DEUTSCHE INV MGMT AMERICAS INC & 76960 & DEUTSCHE & 13 \\
\hline DIMENSIONAL FD ADVISORS, INC. & 23000 & DIMENSIONAL & 14 \\
\hline DIMENSIONAL FD ADVISORS, L.P. & 23000 & DIMENSIONAL & 14 \\
\hline DIMENSIONAL FUND ADVISORS, INC & 23000 & DIMENSIONAL & 14 \\
\hline DIMENSIONAL FUND ADVISORS, LP & 23000 & DIMENSIONAL & 14 \\
\hline DODGE \& COX & 23270 & DODGE & 15 \\
\hline DODGE \& COX, INC. & 23270 & DODGE & 15 \\
\hline FIDELITY INTERNATL LTD & 27700 & FIDELITY & 16 \\
\hline FIDELITY INTL LTD & 27700 & FIDELITY & 16 \\
\hline FIDELITY MANAGEMENT \& RESEARCH & 27800 & FIDELITY & 16 \\
\hline FIDELITY MGMT \& RESEARCH (US) & 27800 & FIDELITY & 16 \\
\hline FIDELITY MGMT \& RESEARCH CO & 27800 & FIDELITY & 16 \\
\hline FRANKLIN RESOURCES INC & 39300 & FRANKLIN & 17 \\
\hline FRANKLIN RESOURCES, INC. & 39300 & FRANKLIN & 17 \\
\hline GEODE CAPITAL MGMT, L.L.C. & 10039 & GEODE & 18 \\
\hline GOLDMAN SACHS ASSET MGMT (US) & 7871 & GOLDMAN & 19 \\
\hline GOLDMAN CAPITAL MGMT, INC. & 10191 & GOLDMAN & 19 \\
\hline GOLDMAN SACHS \& COMPANY & 41260 & GOLDMAN & 19 \\
\hline J. P. MORGAN INVT MGMT (US) & 58835 & MORGAN & 20 \\
\hline J.P MORGAN CHASE \& CO. & 58835 & MORGAN & 20 \\
\hline JP MORGAN \& COMPANY INC & 58835 & MORGAN & 20 \\
\hline JP MORGAN CHASE \& CO & 58835 & MORGAN & 20 \\
\hline JPMORGAN CHASE \& CO. & 58835 & MORGAN & 20 \\
\hline JPMORGAN CHASE \& COMPANY & 58835 & MORGAN & 20 \\
\hline JANUS CAPITAL CORPORATION & 48170 & JANUS & 21 \\
\hline JANUS CAPITAL MANAGEMENT LLC & 48170 & JANUS & 21 \\
\hline JENNISON ASSOCIATES LLC & 48360 & JENNISON & 22 \\
\hline LEGG MASON PRIV PTF GRP, LLC & 12054 & LEGG & 23 \\
\hline LEGG MASON ASSET MGMT(JPN)CO.L & 12056 & LEGG & 23 \\
\hline LEGG MASON INTL EQUITIES & 12057 & LEGG & 23 \\
\hline LEGG MASON INVT COUNSEL, LLC & 12059 & LEGG & 23 \\
\hline LEGG MASON TRUST & 12064 & LEGG & 23 \\
\hline LEGG MASON PTNR FD ADVR L L C & 13273 & LEGG & 23 \\
\hline LEGG MASON GBL ASSET ALLOC LLC & 13586 & LEGG & 23 \\
\hline QS LEGG MASON GBL ASSET ALLOC & 13586 & LEGG & 23 \\
\hline LEGG MASON CAPITAL MANAGEMENT & 50130 & LEGG & 23 \\
\hline LEGG MASON CAPITAL MGMT INC. & 50130 & LEGG & 23 \\
\hline LEGG MASON CAPITAL MGMT, INC. & 50130 & LEGG & 23 \\
\hline LEGG MASON CAPITAL MGMT, LLC & 50130 & LEGG & 23 \\
\hline LEGG MASON FUND ADVISORS, INC. & 50160 & LEGG & 23 \\
\hline LEGG MASON INC & 50160 & LEGG & 23 \\
\hline MASSACHUSETTS FINANCIAL SERVIC & 54600 & MASSACHUSETTS & 24 \\
\hline MASSACHUSETTS FINL SERVICES CO & 54600 & MASSACHUSETTS & 24 \\
\hline MELLON PRIV WEALTH MGMT(THE AR & 4445 & MELLON & 25 \\
\hline BNY MELLON ASSET MANAGEMENT & 6890 & MELLON & 25 \\
\hline MELLON BANK NA & 55390 & MELLON & 25 \\
\hline MELLON PRIVATE ASSET MGMT & 55390 & MELLON & 25 \\
\hline MELLON PRIV WEALTH MGMT (PGIA) & 71550 & MELLON & 25 \\
\hline MERRILL LYNCH ASSET MGMT INC. & 39539 & MERRILL & 26 \\
\hline MERRILL LYNCH INV MANAGERS(NJ) & 39539 & MERRILL & 26 \\
\hline MERRILL LYNCH INVESTMENT MANAG & 39539 & MERRILL & 26 \\
\hline MERRILL LYNCH \& CO INC & 56780 & MERRILL & 26 \\
\hline MERRILL LYNCH CAPITAL MARKETS & 56780 & MERRILL & 26 \\
\hline
\end{tabular}


Table A.III. (continued): Aggregation at the Fund-Family Level

\begin{tabular}{|c|c|c|c|}
\hline Manager Name & Manager Number & Keyword & Family Number \\
\hline MERRILL LYNCH INV MANAGERS CO. & 56790 & MERRILL & 26 \\
\hline MERRILL LYNCH INV MANAGERS LTD & 56790 & MERRILL & 26 \\
\hline MERRILL LYNCH MERCURY ASSET MA & 56790 & MERRILL & 26 \\
\hline MERRILL LYNCH MERCURY ASSET MG & 56790 & MERRILL & 26 \\
\hline MERRILL LYNCH INV MANAGERS(UK) & 91430 & MERRILL & 26 \\
\hline MERRILL LYNCH INVESTMENT MANAG & 91430 & MERRILL & 26 \\
\hline MFS INVT MGMT CNDA LIMITED & 6013 & MFS & 27 \\
\hline MFS MCLEAN BUDDEN & 6013 & MFS & 27 \\
\hline MFS INVESTMENT MANAGEMENT & 54600 & MFS & 27 \\
\hline MSDW \& COMPANY & 58950 & MSDW & 28 \\
\hline MSDW ADVR INC. & 58950 & MSDW & 28 \\
\hline NORTHERN TRUST VALUE INVESTORS & 23365 & NORTHERN & 29 \\
\hline NORTHERN TRUST COMPANY & 65260 & NORTHERN & 29 \\
\hline NORTHERN TRUST CORP & 65260 & NORTHERN & 29 \\
\hline NORTHERN TRUST GLOBAL INVTS & 65260 & NORTHERN & 29 \\
\hline NORTHERN TRUST COMPANY OF CONN & 72490 & NORTHERN & 29 \\
\hline NORTHERN TRUST COMPANY OF CT & 72490 & NORTHERN & 29 \\
\hline PUTNAM INVESTMENTS LLC. & 13667 & PUTNAM & 30 \\
\hline PUTNAM INVESTMENT MANAGEMENT & 72400 & PUTNAM & 30 \\
\hline PUTNAM INVESTMENT MGMT, L.L.C. & 72400 & PUTNAM & 30 \\
\hline PUTNAM INVESTMENT MGMT, LLC & 72400 & PUTNAM & 30 \\
\hline PUTNAM INVESTMENTS LLC. & 13667 & PUTNAM & 30 \\
\hline PUTNAM INVESTMENT MANAGEMENT & 72400 & PUTNAM & 30 \\
\hline PUTNAM INVESTMENT MGMT, L.L.C. & 72400 & PUTNAM & 30 \\
\hline PUTNAM INVESTMENT MGMT, LLC & 72400 & PUTNAM & 30 \\
\hline STATE STR GBL ADVR IRELAND LTD & 5960 & STATE & 31 \\
\hline STATE STR BK \& TRUST CO BOSTON & 81540 & STATE & 31 \\
\hline STATE STR CORPORATION & 81540 & STATE & 31 \\
\hline STATE STR RESEARCH \& MANAGEMEN & 81575 & STATE & 31 \\
\hline STATE STR RESEARCH \& MGMT CO & 81575 & STATE & 31 \\
\hline STATE STR RESEARCH \& MGMT CO. & 81575 & STATE & 31 \\
\hline T. ROWE PRICE ASSOCIATES, INC. & 71110 & ROWE & 32 \\
\hline TAUNUS CORPORATION & 7800 & TAUNUS & 33 \\
\hline VANGUARD GROUP & 90457 & VANGUARD & 34 \\
\hline VANGUARD GROUP, INC. & 90457 & VANGUARD & 34 \\
\hline WACHOVIA ASSET MANAGEMENT & 91000 & WACHOVIA & 35 \\
\hline WACHOVIA BANK N.A. & 91000 & WACHOVIA & 35 \\
\hline WACHOVIA CORPORATION & 91000 & WACHOVIA & 35 \\
\hline WELLINGTON MANAGEMENT CO, LLP & 91910 & WELLINGTON & 36 \\
\hline WELLINGTON MANAGEMENT COMPANY, & 91910 & WELLINGTON & 36 \\
\hline WELLINGTON MGMT CO, L.L.P. & 91910 & WELLINGTON & 36 \\
\hline
\end{tabular}

This table shows how individual managers in the Thomson-Reuters (TR) database are grouped into families. The first column shows all unique occurrences of the character string that belong to each family in the TR database. The second column is the manager number assigned by TR, the third column is the keyword that we used to search for each manager and the last column represents the fund family to which the individual manager was assigned. 


\section{Appendix IV. Bankruptcy Disclosure}

Figure A.1. United Airline 2006: Disclosure Statement Sample

\section{UAL Corporation: Summary of Classification and Treatment of Claims and Interests}

\begin{tabular}{|c|c|c|c|}
\hline Class & Claim & Plan Treatment of Class & $\begin{array}{c}\text { Projected } \\
\text { Recovery } \\
\text { Under the Plan }\end{array}$ \\
\hline $1 \mathrm{~A}$ & DIP Facility Claims & Paid in full & $100.0 \%$ \\
\hline 1B-1 & Secured Aircraft Claims & $\begin{array}{l}\text { Reinstated; such treatment as to which UAL or } \\
\text { Reorganized UAL and the Secured Aircraft Creditor } \\
\text { will have agreed in writing; return of collateral; or } \\
\text { treatment otherwise rendering such Secured Aircraft } \\
\text { Claim Unimpaired }\end{array}$ & $100.0 \%$ \\
\hline $1 \mathrm{~B}-2$ & Other Secured Claims & $\begin{array}{l}\text { Reinstated; paid in full in Cash; return of collateral; } \\
\text { or treatment otherwise rendering such Other Secured } \\
\text { Claim Unimpaired }\end{array}$ & $100.0 \%$ \\
\hline $1 \mathrm{C}$ & Other Priority Claims & Paid in full & $100.0 \%$ \\
\hline 1D & Unsecured Convenience Class Claims & $\begin{array}{l}\text { Pro rata share of the Unsecured Convenience } \\
\text { Class Distribution }\end{array}$ & $4-8 \%$ \\
\hline $1 \mathrm{E}-1$ & Unsecured Retained Aircraft Claims & Pro rata share of the Unsecured Distribution & $4-8 \%$ \\
\hline $1 \mathrm{E}-2$ & Unsecured Rejected Aircraft Claims & Pro rata share of the Unsecured Distribution & $4-8 \%$ \\
\hline $1 \mathrm{E}-3$ & Other Unsecured Claims & Pro rata share of the Unsecured Distribution & $4-8 \%$ \\
\hline $1 \mathrm{~F}$ & TOPrS Claims & $\begin{array}{l}\text { Not entitled to receive any distribution or retain any } \\
\text { property under the Plan }\end{array}$ & $0 \%$ \\
\hline $1 \mathrm{G}$ & Preferred Stock Interests & $\begin{array}{l}\text { Not entitled to receive any distribution or retain any } \\
\text { property under the Plan }\end{array}$ & $0 \%$ \\
\hline $1 \mathrm{H}$ & Common Stock Interests & $\begin{array}{l}\text { Not entitled to receive any distribution or retain any } \\
\text { property under the Plan }\end{array}$ & $0 \%$ \\
\hline $1 \mathrm{I}$ & Subordinated Securities Claims & $\begin{array}{l}\text { Not entitled to receive any distribution or retain any } \\
\text { property under the Plan }\end{array}$ & $0 \%$ \\
\hline
\end{tabular}

This figure corresponds to page 3 of United Airline's Disclosure Statement, recovered from this carrier's SEC 8K filing. The disclosure statement provides creditors with adequate information regarding the state of the insolvent firm, as well as the reorganization plan, including the distribution to all claimants. For our purpose, we collect data on any distribution to equity holders, who are termed "interests" in this context. Here we see that pre-bankruptcy equity holders receive no recovery (distribution) in the reorganization plan. 
Figure A.2. Distribution of $H H I \Delta$ Under Different Bankruptcy Assumptions

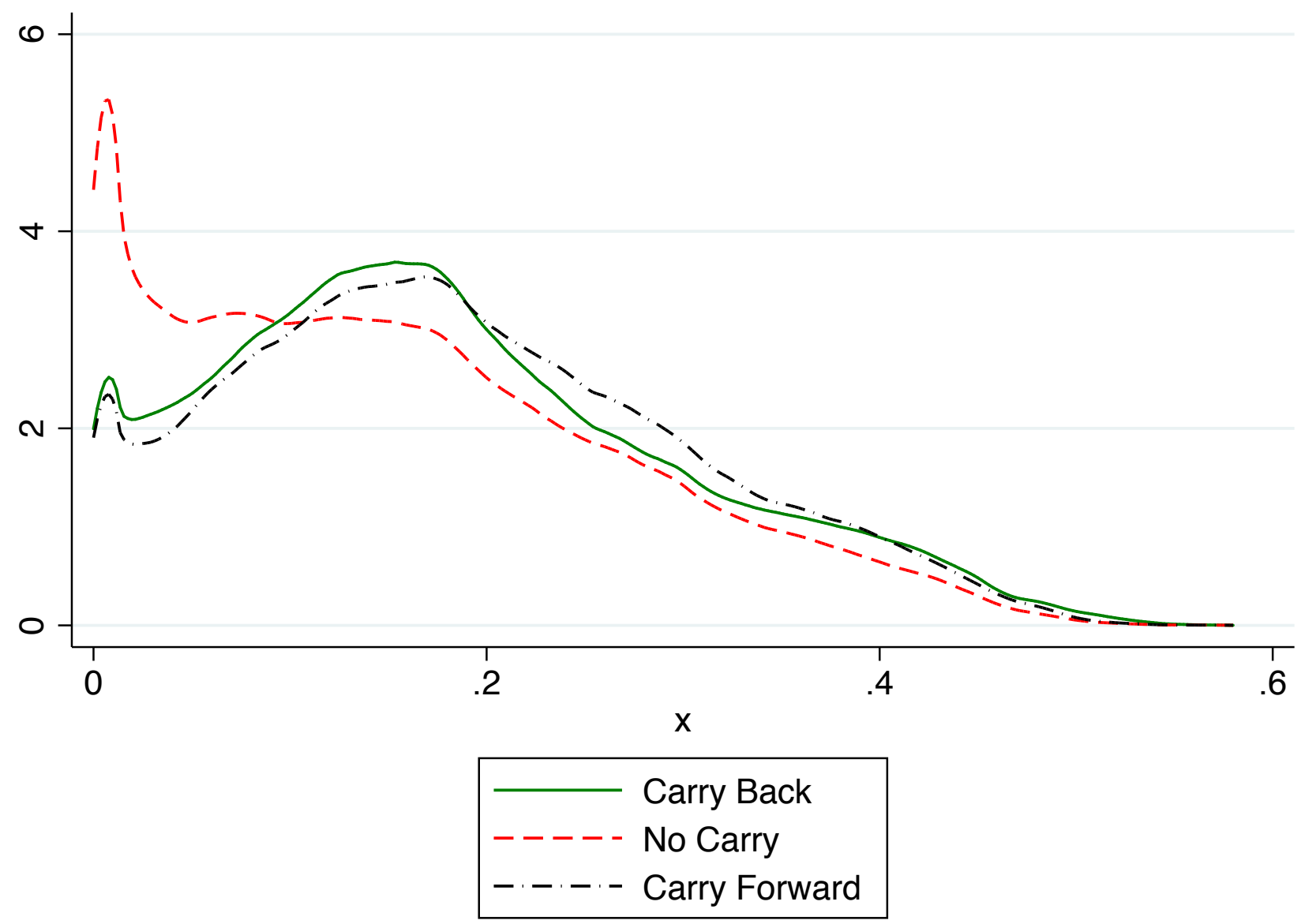

This figure displays the distribution of HHIS under the three different assumptions of cash flow and control rights in bankruptcy. Carrying the last observed ownership and control measure prior to bankruptcy forward throughout the bankruptcy period (black dot-dashed line) compared to carrying the first observed cash flow and control rights after emerging from bankruptcy backward throughout the bankruptcy period (green solid line) does not materially affect the distribution of $H H I \Delta$. These alternative assumptions change the ownership and control parameters in HHI $\Delta\left(\gamma_{i j} \mathrm{~s}\right.$ and $\left.\beta_{i j} \mathrm{~s}\right)$, but do not significantly affect the market share component. In contrast, the distribution changes when we assume zero ownership and control in bankruptcy (red dashed line). Specifically, this assumption sets $\gamma_{i j}=\beta_{i j}=0$, and thus significantly increases the number of markets with zero common ownership. In setting the ownership and control parameters to zero, the effective time-series variation in the market share component materially changes (since it enters the $H H I \Delta$ formula multiplicatively). 


\section{Appendix V. Voting Rights}

Table A.IV. Investors Who Report the Most Equity Shares with "No" Voting Rights

\begin{tabular}{lrrr}
\hline Voting Rights Designation: & Sole & Shared & \multicolumn{1}{c}{ No } \\
\hline Fidelity & $8.1 \%$ & $0.7 \%$ & $91.2 \%$ \\
PRIMECAP Management & $21.2 \%$ & $0.1 \%$ & $78.6 \%$ \\
T. Rowe Price & $24.8 \%$ & $0.0 \%$ & $75.2 \%$ \\
Capital Research Global Investors & $49.5 \%$ & $2.4 \%$ & $48.1 \%$ \\
Wellington Management & $45.7 \%$ & $7.7 \%$ & $46.6 \%$ \\
Gilder, Gagnon, Howe \& Co. & $3.2 \%$ & $0.0 \%$ & $96.8 \%$ \\
Old Lane & $0.0 \%$ & $0.0 \%$ & $100.0 \%$ \\
Vanguard Group & $26.5 \%$ & $2.3 \%$ & $71.2 \%$ \\
U.S. Trust Company & $55.7 \%$ & $1.7 \%$ & $42.6 \%$ \\
Selz Capital & $35.2 \%$ & $0.0 \%$ & $64.8 \%$ \\
\hline
\end{tabular}

This table displays the top 10 investors who report the most airline shares for which they do not hold voting rights in the Thomson-Reuters database. For each investor, the table breaks down the fraction of shares reported as "sole", "shared", and "no" voting rights. 